the European Ceramic Society

Elsevier Editorial System(tm) for Journal of

Manuscript Draft

Manuscript Number:

Title: From bulk to cellular structures: a review on ceramic/graphene composites

Article Type: SI: WGCC 2016

Keywords: graphene; ceramics; composites; coatings; cellular materials

Corresponding Author: Professor Pilar Miranzo, Prof

Corresponding Author's Institution: Instituto de Ceramica y Vidrio, CSIC

First Author: Pilar Miranzo, Prof

Order of Authors: Pilar Miranzo, Prof; Manuel Belmonte; Isabel Osendi

Abstract: The updated results on the relevant properties of graphene reinforced ceramic are reviewed. The representative data for a wide number of bulk composites are compared, making special emphasis on the mechanical properties (fracture toughness, strength), wear and friction characteristics, and elastic properties. The electrical functionality boosted by the contacted graphene network is critically assessed for conducting and dielectric matrices. Regarding thermal transport, the enhancement or depletion of thermal conductivity is revised considering for different matrices and for specific orientations. Furthermore, new developments on layered and coatings, as well as in cellular composites that certainly widen the scope of applications for these remarkable group of ceramic composites are looked over.

Suggested Reviewers: Czaba Balazsi

balazsi.csaba@energia.mta.hu

Expert in ceramic/graphene composites

Akira Kawasaki

kawasakietohoku.ac.jp

Expert in ceramic/graphene composites

Jan Dusza

jdusza@imr.saske.sk

Expert in ceramic/graphene composites 
1

\title{
From bulk to cellular structures: a review on ceramic/graphene composites
}

\author{
Pilar Miranzo ${ }^{1}$, Manuel Belmonte, M.I. Osendi
}

Institute of Ceramics and Glass (ICV-CSIC), Kelsen 5, 28049 Madrid (Spain)

\begin{abstract}
The updated results on the relevant properties of graphene reinforced ceramic are reviewed. The representative data for a wide number of bulk composites are compared, making special emphasis on the mechanical properties (fracture toughness, strength), wear and friction characteristics, and elastic properties. The electrical functionality boosted by the contacted graphene network is critically assessed for conducting and dielectric matrices. Regarding thermal transport, the enhancement or depletion of thermal conductivity is revised considering for different matrices and for specific orientations. Furthermore, new developments on layered and coatings, as well as in cellular composites that certainly widen the scope of applications for these remarkable group of ceramic composites are looked over.
\end{abstract}

\section{Keywords: graphene; ceramics; composites; coatings; cellular materials}

\section{Introduction}

The research on graphene reinforced ceramics started very timidly about six years ago, and ever since the interest of the scientific community has steadily grown owing to the relevant

${ }^{1}$ Corresponding author. Phone: +34-917355872; Fax: +34-917355843. E-mail: pmiranzo@icv.csic.es (P. Miranzo) 
properties that these graphene-based nanostructures impart on most ceramics. The benefits produced by these fillers are highly linked to the extraordinary properties of graphene, which have been described in excellent reviews [1,2]. Quite important subjects as the dispersability and stability of graphene nanostructures in solvents, and particularly for making reliable composites, have also been treated abundantly and extensive works tackled this matter $[3,4]$. Concentrating on ceramic/graphene composites, a notable augment of the numbers of publications on these composites is observed and even few publications reviewing these materials already exist, the early one by Porwal et al. [5] and two recent review papers by Markandan et al. [6] and Nieto et al. [7]. The processing of graphenebased composites, with specific mention to the graphene synthesis methods and their mixing with the matrices, as well as available densification methods, have been broadly revised in these previous reviews. Hence, present appraisal focusses on the effect of these fillers over the materials properties bringing to light common results and pointing out possible discrepancies. Concerning mechanical and tribological properties, this review contrasts the abundant results on toughness, wear and friction, but also reports on less common data about strength and elastic properties. We also make mention of the testing method and filler type when comparing outcomes. In the same way, for the electrical functionality that graphene fillers frequently impart to composites, the centre of attention is on the changes of the electrical conductivity with the filler concentration for different types of materials and with temperature as well; and also referring the scarce studies on thermopower characteristics. As for the thermal conductivity -marginally addressed in previous reviews- is now treated in more detail following same rationale. The above subjects are condensed in the sections 2 to 5 , as most of the accumulated knowledge certainly pertains to bulk type composites. Works on layered materials, ceramic coatings 
and cellular structures of these composites are slowly emerging; accordingly, a separate section (section 6) is devoted to these new advancements, including layered structures (section 6.1), coatings (section 6.2) and also cellular composites (section 6.3). In all these cases, as they are more recent, a succinct reference to the processing methods has been carried out. The multi-functionality of this family of composites is conveniently emphasized along this study but also their flexibility, in the sense of the options that graphene nanostructures offer for creating new forms and structures, which presumably would multiply their potential for a wide range of new applications.

\section{Mechanical properties of bulk ceramic/graphene composites}

The research on ceramic/graphene composites has been mostly focused on enhancing the mechanical properties of ceramics and particularly of the fracture toughness parameter or $\mathrm{K}_{\mathrm{IC}}$. Former studies were aimed at $\mathrm{Al}_{2} \mathrm{O}_{3}$ and $\mathrm{Si}_{3} \mathrm{~N}_{4}$ ceramics [8-11], hence being presently the most extensively analysed systems [12-18], although now we can find studies on many ceramics of interest, such as $\mathrm{SiC}, \mathrm{ZrO}_{2}, \mathrm{ZrB}_{2}, \mathrm{~B}{ }_{4} \mathrm{C}, \mathrm{TaC}, \mathrm{TiC}, \mathrm{Ti}_{3} \mathrm{Si}_{2} \mathrm{C}, \mathrm{SiO}_{2}$ or hydroxyapatite (HA) [19-34]. A general outcome from the available $\mathrm{K}_{\mathrm{IC}}$ data is the attested toughening effect induced by the graphene nanostructures. This particularly applies when composites are mechanically tested in the most favourable direction, which is coincident with the loading axis defined by the processing method-commonly the SPS method-. Nonetheless, it remains a challenge to assign the commonly observed reinforcement to a precise toughening mechanism, as it can be seen in Figure 1, where representative figures for fracture toughness increments $\left(\Delta \mathrm{K}_{\mathrm{IC}}\right)$ in a wide range of composites have been plotted. $\Delta \mathrm{K}_{\mathrm{IC}}$ data points appear widely scattered, although a consistent difference emerges by 
enclosing most of the data pertaining to reduced graphene oxide (rGO) and graphene nanoplatelets (GNP) filler composites separately, as the systems with rGO reinforcements generally realize higher $\Delta \mathrm{K}_{\mathrm{IC}}$ at lower filler fractions.

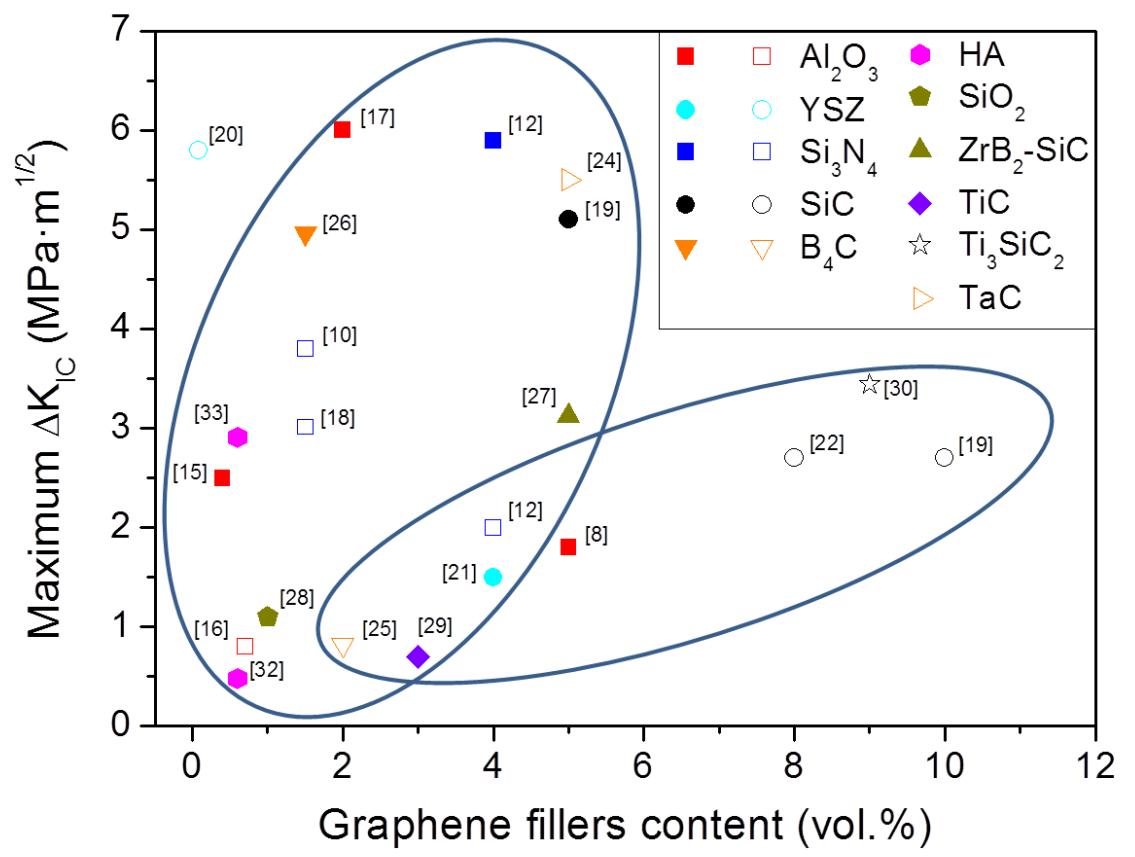

Figure 1. $\Delta \mathrm{K}_{\mathrm{IC}}$ data for different ceramic/graphene composites replotted from literature indicating the composite and the filler types (full and empty symbols correspond to GO and GNP fillers, respectively). Numbers in brackets show the corresponding references.

At this point, it should be mentioned that many studies use the Vickers indentation technique (IF) for determining $\mathrm{K}_{\mathrm{IC}}$; but this method is often controversial and raises criticisms about its validity, which keenly depends on the contact-mechanical response of the material; as it has been pointed by Wang et al. [35], this is especially critical in the case of anisotropic materials, nanocomposites or ceramics sufficiently weak in shear, as 
considerable redistribution of stresses can take place under the indenter, resulting in the absence of the classical radial cracks $[19,36]$. In Figure 2 some examples of this phenomenon for $\mathrm{Si}_{3} \mathrm{~N}_{4}$ and $\mathrm{SiC}$ nanocomposites with $\mathrm{rGO}$ and GNP fillers are illustrated.

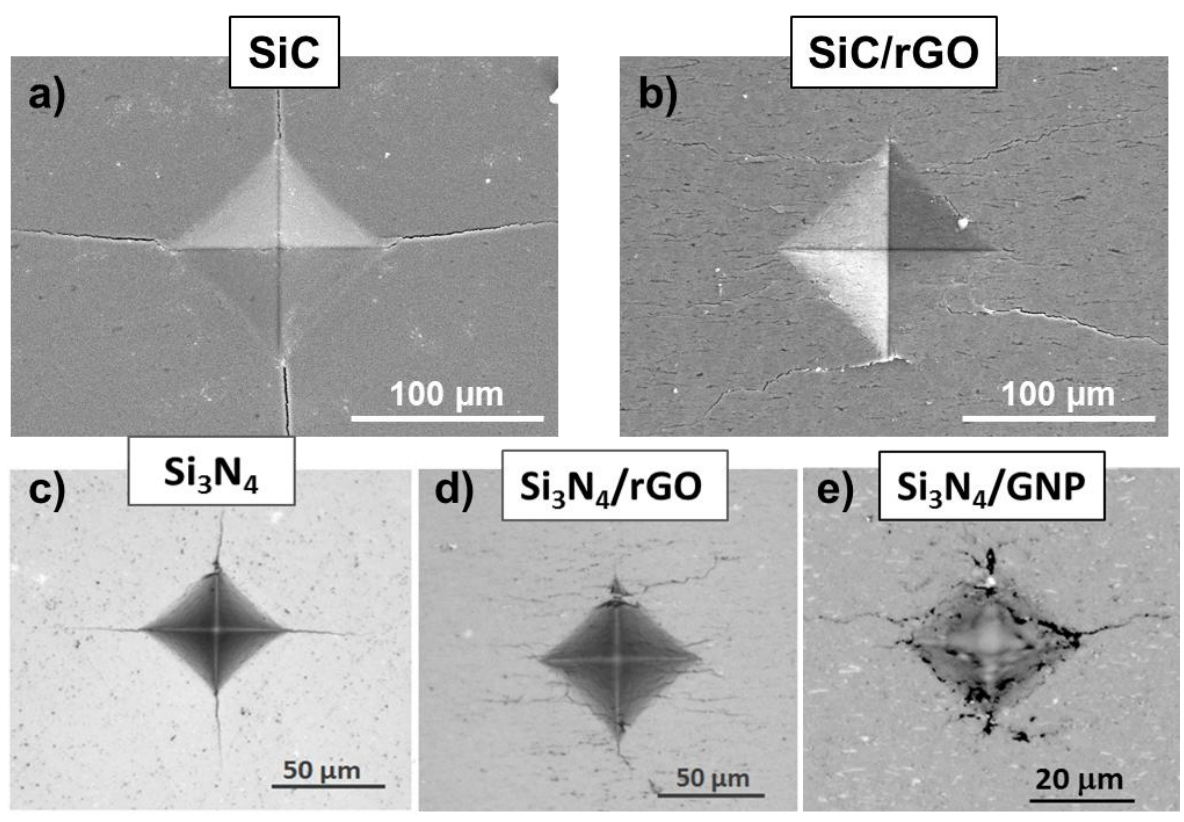

Figure 2. Examples of indentation prints on $\mathrm{SiC}$ (a) $\mathrm{SiC} / \mathrm{rGO}$ (b), $\mathrm{Si}_{3} \mathrm{~N}_{4}$ (c) $\mathrm{Si}_{3} \mathrm{~N}_{4} / \mathrm{rGO}$ (d) and $\mathrm{Si}_{3} \mathrm{~N}_{4} / \mathrm{GNP}$ (e) composites, from references $[19,36]$.

On the other hand, there is a large variability in the range of loads employed by different researchers (inferior $1 \mathrm{~N}$ to above $100 \mathrm{~N}$ ) -nominally without clear mention to the appropriate load range that assures neat and well developed cracks- as well as the gamut of indentation expressions used. Hence, comparison among different materials can be abstruse. To extract general trends from the existing data that could be more meaningful, we can make the effort of plotting the best results reported for each material system, indicating the type of graphene nanostructure, i.e. pristine GNP or GO, and for lesser controverted $\mathrm{K}_{\mathrm{IC}}$ tests. Accordingly, we have taken published $\mathrm{K}_{\mathrm{IC}}$ data measured by 
standard methods like the surface crack on flexure (SCF), single edge pre-cracked beam (SEPB) and chevron notch beam (CNB) but also including single edge notch beam (SENB) data, all for the most favourable orientation, that is for crack propagating perpendicular to the graphene plane. In Figure 3, the relative toughness $\left(\Delta \mathrm{K}_{\mathrm{IC}} / \mathrm{K}_{\mathrm{IC} \text { matrix }}\right)$ data are represented as a function of the graphene filler volume content, observing that increments for composites with GO vary between 45 and $160 \%$ whereas for GNP materials fluctuate in the interval $20-85 \%$, hence again confirming comparatively higher reinforcement when using GO fillers.

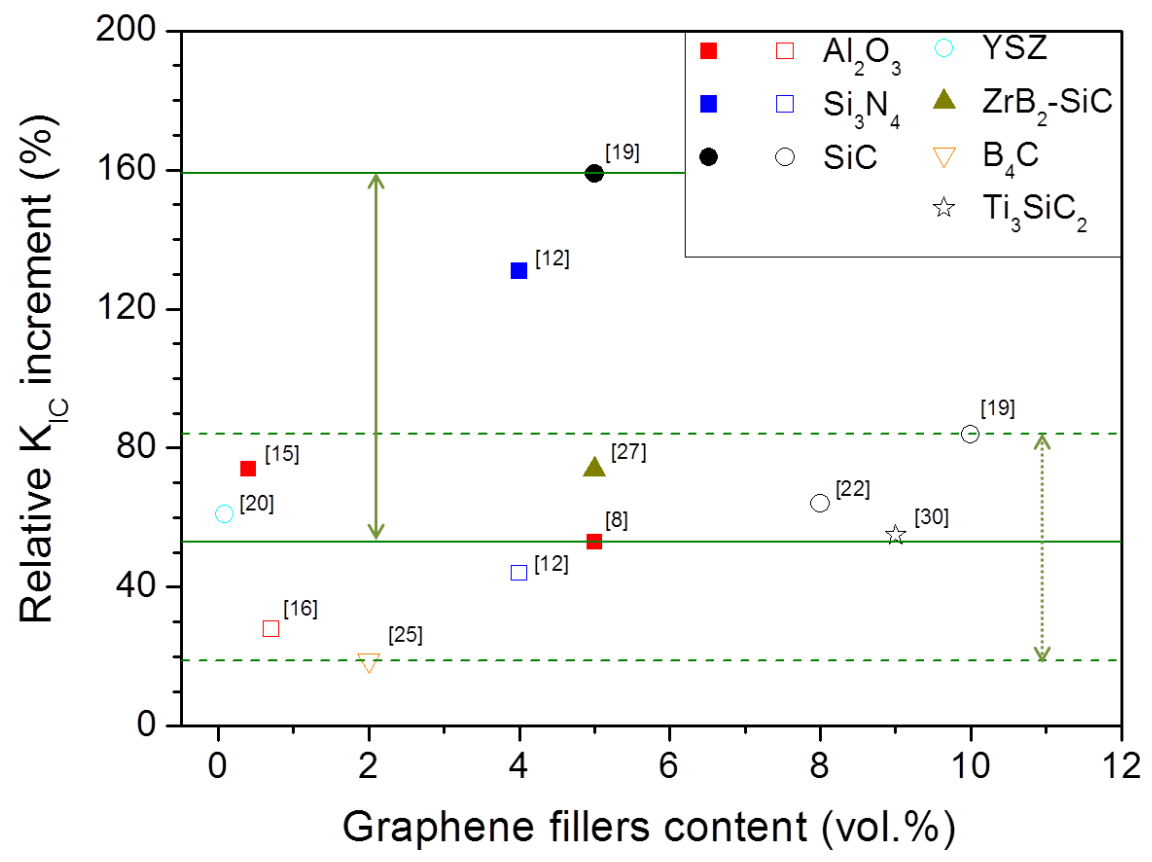

Figure 3. Relative $\mathrm{K}_{\mathrm{IC}}$ increment $\left(\Delta \mathrm{K}_{\mathrm{IC}} / \mathrm{K}_{\mathrm{IC} \text { matrix }}\right)$ as a function of the volume fraction of graphene fillers (full and empty symbols correspond to GO and GNP fillers, respectively). Different materials are included, plotted from published data (corresponding references are in brackets) excluding indentation test results. 
It is also interesting to realize that $\mathrm{K}_{\mathrm{IC}}$ displays more variability for $\mathrm{GO}$ composites, probably because the proportion of defects in GO sheets and accordingly their crystallinity depend on the temperature achieved during the sintering process, actually producing different GO materials; conversely, composites with GNP type fillers show lesser toughening variability (Figs. 1 and 3).

Microscopic observation of indentation cracks often reveals the occurrence of both bridging and deflection of crack paths by these nanostructures, while images of fracture surfaces frequently unveil the occurrence the pulling-out of platelets (see some examples in Fig. 4). Crack bridging is a well-known reinforcing mechanism for fibre and whisker composites, where these filament-like structures act as elastic ligaments that bridge the two sides of the crack, thereby imparting crack-closing forces [37]. Additionally, phenomena as crack deflection and the pulling-out of fibres from the matrix suppose extra mechanisms for dissipation of energy and accordingly of toughening [38]. The nature of the interfacial bond between the fibre and matrix plays a profound role on the failure mechanisms of composites; in fact all these mechanisms are favoured if interfacial bond is weak [38].

Development of specific models for present composites and comparison with sound experimental data -including estimation of bridging force- is yet to come. Also deeper analyses of interfacial characteristics using high resolution transmission electron microscopy (HRTEM) tools are required for the different composites in connection with studies of the respective matrix materials. 
Deflection/branching

\section{Exfoliation}
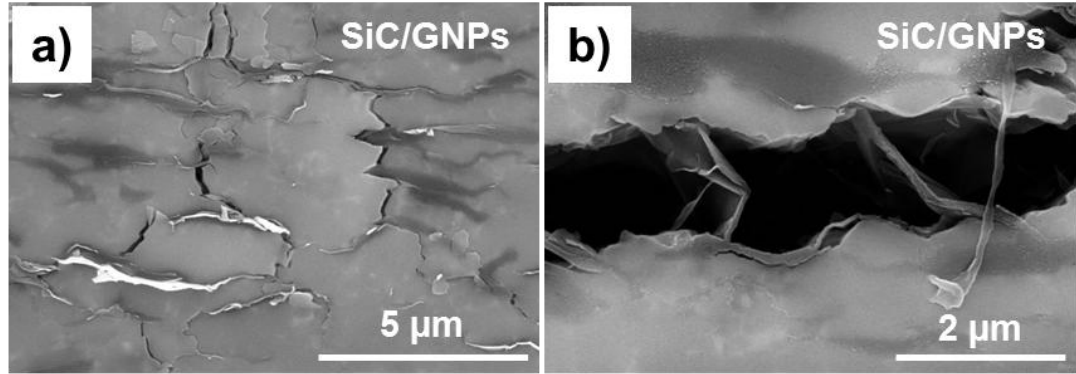

Pull-out

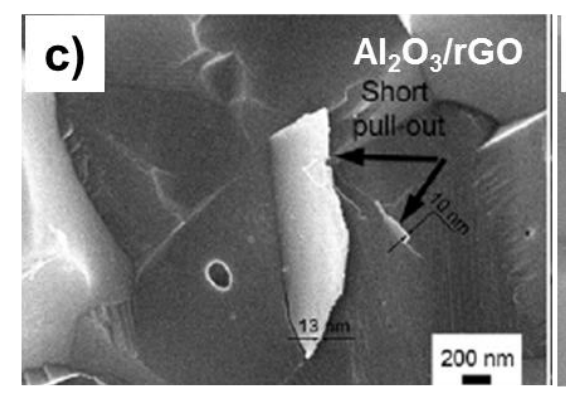

Bridging

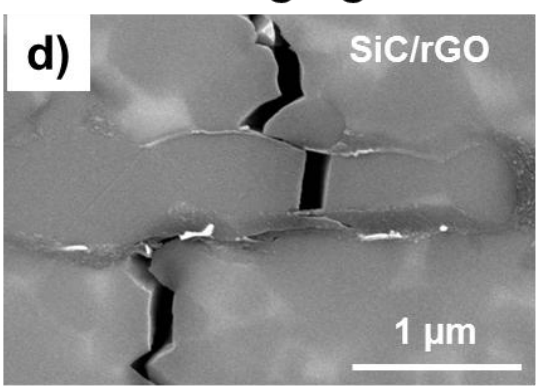

\section{Bridging $\rightarrow$ pull-out}

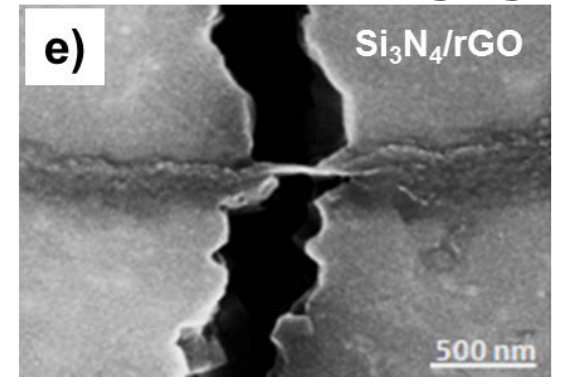

f)

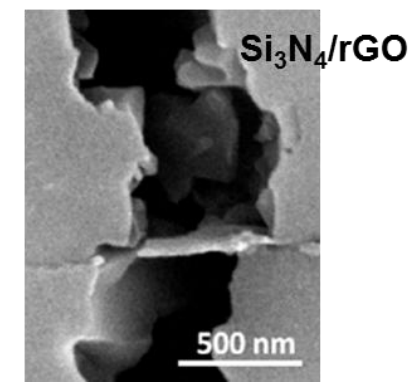

Figure 4. Examples of the interference of the flat nanostructures with crack paths in ceramic/graphene composites. Adapted from references [12, 19, 39].

Notwithstanding the above, we can mention that Ramirez and Osendi [40] obtained a reasonable fitting for the different toughening observed in $\mathrm{Si}_{3} \mathrm{~N}_{4}$ ceramics when using two types of graphene fillers, rGO and GNP, using a classical bridging model [41] developed for fibre composites, considering the most favourable orientation. With this model, the main contribution of bridging to the toughening of ceramic/graphene composites is proved 
as in fact occurs in fibre composites, where the energy dissipated during crack propagation due to deflection and pull-out mechanisms is comparatively lower. We should also notice the work of Ovid'ko and Sheinerman [42] that used the boundary element method to describe fracture toughness for composites with randomly oriented nanoplatelets by using a crack-deflection model (in 2 dimensions). These authors suggest that higher toughness increment ( $\geq 100 \%$ ) observed for some composites (see Figs. 1 and 3) would need a new model including the above-mentioned of bridging and pull-out mechanisms. Moreover, the undulation typically observed (Fig. 5) for thin graphene sheets -common in composites with GO fillers- is also suggested as a potential reinforcing mechanisms [42, 43] for these materials.
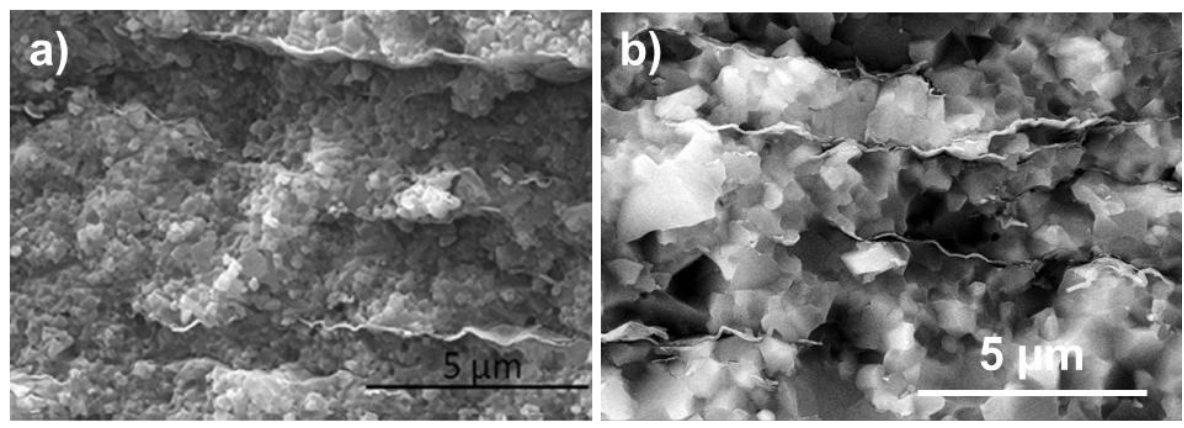

Figure 5. Fracture surface of $\mathrm{Si}_{3} \mathrm{~N}_{4} / \mathrm{rGO}$ (a) and $\mathrm{SiC} / \mathrm{rGO}$ (b) composites showing undulating sheets. Adapted from references [12,19].

Strength $\left(\sigma_{\mathrm{f}}\right)$ has also been measured in these materials, although the number of available data is comparatively lower than for $\mathrm{K}_{\mathrm{IC}}$, the commonly used test being the 3-point bending of prismatic bars, because the relatively small size of the specimens processed in most cases. A summary of the best data reported for each material is plotted in Figure 6, observing that the highest strengthening (100\%) achieved corresponds to volume fraction in 
the $4-6 \%$ range. For fillers contents below and above that range limit, the strengthening generally declines $[15,44]$ as fillers probably act like flaws. Hence, the effects of the flaw size and the enhanced toughness compete and a maximum strength is achieved when the flaw size is counterbalance by the toughening increment. Additionally, certain flaw tolerance has been described in $\mathrm{Al}_{2} \mathrm{O}_{3} / \mathrm{rGO}$ composites [15] associated to the R-curve behaviour, which they determined for these composites using an indirect method.

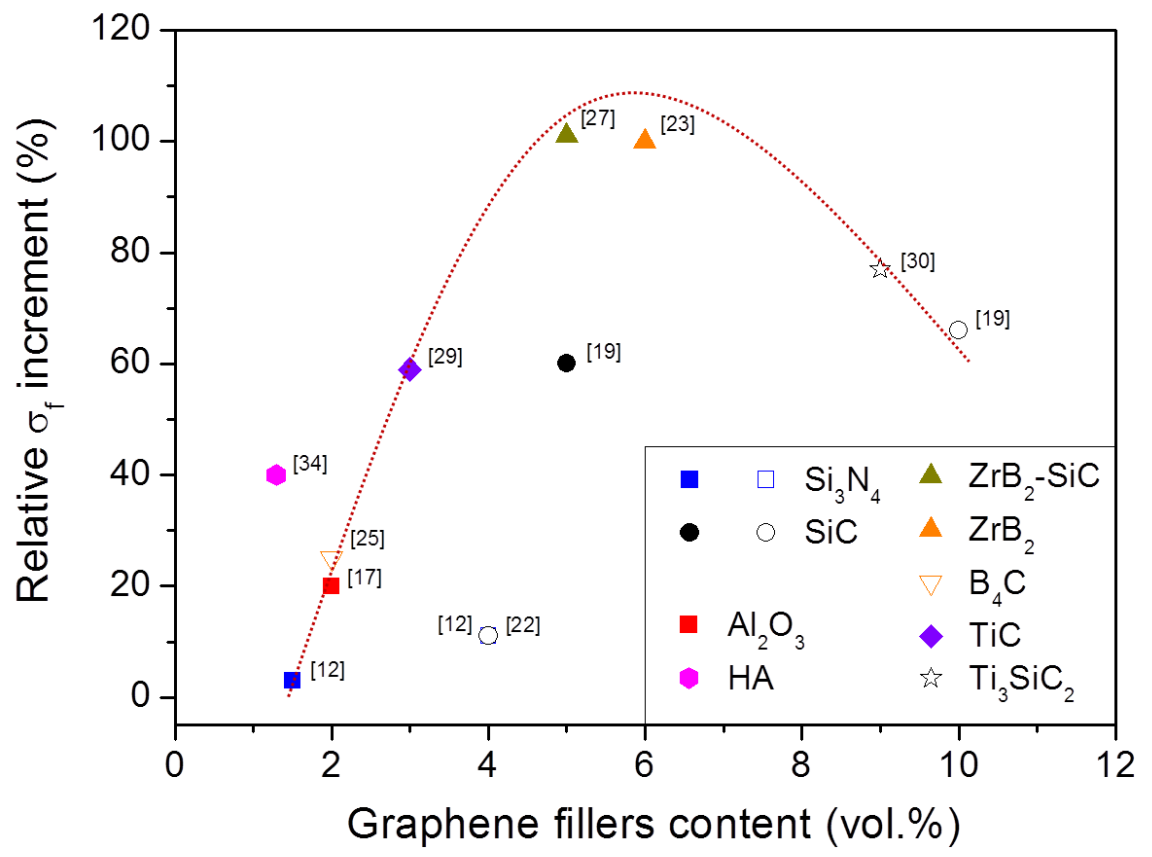

Figure 6. Top relative strength increases $\left(\Delta \sigma_{f} / \sigma_{\text {fmatrix }}\right)$ for different composites at given graphene volume fractions. Full and empty symbols correspond to GO and GNP fillers, respectively. References are indicated within brackets. All data correspond to 3-point bending tests. The dashed line is drawn as a guide for the eye. 
Relating to the elastic properties, most results indicate a reduction of elastic modulus $(\mathrm{E})$ in composites [13, 16, 36, 43], actually producing a softening effect, in contrast to the high elastic modulus of the graphene monolayer ( 1TPa) [45], although relatively smaller for the GO monolayer (E 0.25 TPa) [46]. Detailed studies by Seiner et al. [36, 43] using resonant ultrasound spectroscopy (RUS) and computer simulations of the resonance spectrum show a noticeable anisotropy for $\mathrm{Si}_{3} \mathrm{~N}_{4} /$ graphene composites that grows stronger with the graphene filler content, owing to the preferential alignment of the graphene nanoplateletes and to their own anisotropy as well [47]. Accordingly, decreases of E and shear moduli above $60 \%$ are reported for specific directions, namely, perpendicular to and along the graphene plane, respectively. Figure 7 exemplifies the effects for $\mathrm{E}$ and the Poisson coefficient as a function of orientation. Generally, ceramics show a larger ratio of shear to bulk moduli, which indicates their poor ductility, but the addition of the graphene fillers may be thus expected to decrease this ratio in the composites and consequently enable easier shear induced cracking.
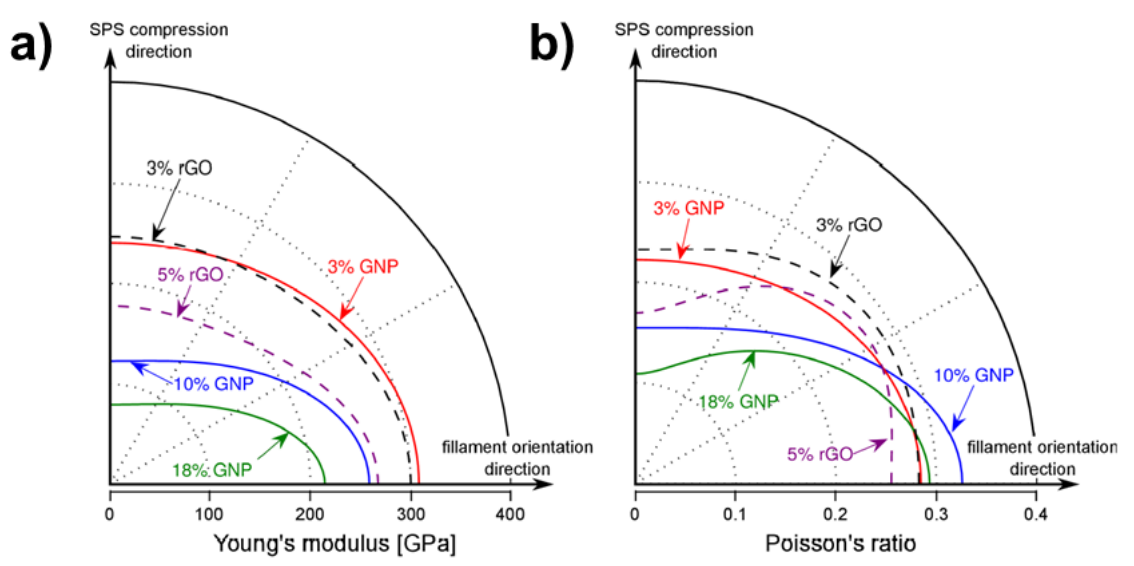

Figure 7. Example of the variations of Young modulus (a) and Poisson coefficient (b) with direction in $\mathrm{Si}_{3} \mathrm{~N}_{4}$ composites with graphene based fillers processed by SPS. The $\mathrm{x}$ axis 
coincides with the orientation plane for fillers, i.e. perpendicular to the SPS loading direction. Two types of fillers are considered, rGO sheets and GNP, and different volume fractions indicated by the numbers next to the filler type [36].

\section{Tribological properties of ceramic/graphene composites}

In addition to the outstanding electronic and physicochemical properties of graphene, the carbon nature of graphene has attracted a great interest for using these nanostructures as self-lubricating solids in ceramic components under demanding friction and wear working conditions. This would be the case in applications such as bearing parts, valves, cutting tools, prosthesis or space airframes. However, despite the unquestionable industrial tribological potential of ceramic/graphene composites, the study of these properties was initiated in a second stage of the development process of these composites, commonly once the mechanical and electrical properties were elucidated, delaying the first reported investigations in the tribology field until 2013. In those first works, Hvizdos et al. [48] and Belmonte et al. [49] showed the potential of graphene fillers for enhancing the tribological performance of $\mathrm{Si}_{3} \mathrm{~N}_{4}$ ceramics, especially increasing the wear resistance in about $60 \%$ under dry [48] and isooctane lubricating [49] testing conditions. Later on, new graphene containing ceramic and glass composites have been explored and, at present, reports on the tribological performance of $\mathrm{Si}_{3} \mathrm{~N}_{4}$ [48-52], $\mathrm{Al}_{2} \mathrm{O}_{3}$ [53-56], $\mathrm{SiC}$ [57], $\mathrm{SiO}_{2}$ [58], bioglass [59] bulk composites, as well as $\mathrm{ZrO}_{2}$ [60], $\mathrm{Y}_{2} \mathrm{O}_{3}-\mathrm{Al}_{2} \mathrm{O}_{3}-\mathrm{SiO}_{2}$ (YAS) [61] and $\mathrm{CaSiO}_{3}$ [62] coating composites, can be found. Table 1 summarizes some relevant information (testing conditions and results) of all these works. 
Table 1. Published works on the tribological performance of ceramic/graphene composites. $\mathrm{RT}=$ room temperature, $\mathrm{NA}=$ not available, $\mathrm{BS}=$ Borosilicate, $\mathrm{SS}=$ stainless steel, $\mathrm{YAS}=$ $\mathrm{Y}_{2} \mathrm{O}_{3}-\mathrm{Al}_{2} \mathrm{O}_{3}-\mathrm{SiO}_{2}$.

\begin{tabular}{|c|c|c|c|c|c|c|c|c|c|c|}
\hline Reference & Material & $\begin{array}{l}\text { Filler } \\
\text { (vol. } \% \text { ) }\end{array}$ & Test & Lubric. & $\begin{array}{c}\mathrm{T} \\
\left({ }^{\circ} \mathrm{C}\right)\end{array}$ & Ball & $\begin{array}{c}\text { Loa } \\
\text { d } \\
\text { (N) }\end{array}$ & $\begin{array}{c}\text { Friction } \\
\text { coefficient }\end{array}$ & $\begin{array}{c}\text { Wear } \\
\text { resistance }\end{array}$ & $\begin{array}{l}\text { Proposed } \\
\text { mechanisms }\end{array}$ \\
\hline $\begin{array}{l}\text { Hvizdos et } \\
\text { al. [48] }\end{array}$ & $\mathrm{Si}_{3} \mathrm{~N}_{4} / \mathrm{GNPS}_{\mathrm{S}}$ & $1.5,4.4$ & $\begin{array}{l}\text { Ball-on- } \\
\text { disc }\end{array}$ & Dry & RT & $\mathrm{Si}_{3} \mathrm{~N}_{4}$ & 5 & No differences & $\begin{array}{l}\uparrow 60 \%(4.4 \\
\text { vol } \%)\end{array}$ & $\begin{array}{l}\text { No tribofilm, improved } \\
\text { KIC }\end{array}$ \\
\hline $\begin{array}{l}\text { Belmonte et } \\
\text { al. [49] }\end{array}$ & $\mathrm{Si}_{3} \mathrm{~N}_{4} / \mathrm{GNPS}$ & 4.4 & $\begin{array}{l}\text { Ball-on- } \\
\text { plate }\end{array}$ & Isooctane & RT & $\mathrm{Si}_{3} \mathrm{~N}_{4}$ & $\begin{array}{l}50- \\
200\end{array}$ & $\downarrow 11 \%$ at $200 \mathrm{~N}$ & $\begin{array}{l}\uparrow 56 \% \text { at } 200 \\
\mathrm{~N}\end{array}$ & Graphene tribofilm \\
\hline $\begin{array}{l}\text { Balko et al. } \\
\text { [50] }\end{array}$ & $\mathrm{Si}_{3} \mathrm{~N}_{4} / \mathrm{GNPS}$ & $1.5,4.4$ & $\begin{array}{l}\text { Ball-on- } \\
\text { disc }\end{array}$ & Dry & $\begin{array}{l}\text { RT- } \\
700\end{array}$ & $\mathrm{Si}_{3} \mathrm{~N}_{4}$ & 5 & Lowest for $\mathrm{Si}_{3} \mathrm{~N}_{4}$ & $\begin{array}{l}\uparrow 94 \% \text { at } 300 \\
{ }^{\circ} \mathrm{C}(1.5 \text { vol. } \%)\end{array}$ & $\begin{array}{l}\text { No tribofilm, improved } \\
\text { KIC }\end{array}$ \\
\hline $\begin{array}{l}\text { Rutkowski } \\
\text { et al. [51] }\end{array}$ & $\mathrm{Si}_{3} \mathrm{~N}_{4} / \mathrm{GNPS}$ & $0.7-11.4$ & $\begin{array}{l}\text { Ball-on- } \\
\text { disc }\end{array}$ & Dry & RT & NA & NA & $\begin{array}{l}\text { Lowest for } 0.7 \\
\text { vol. } \%\end{array}$ & $\begin{array}{l}\text { Lowest for } 1.5 \\
\text { vol } \%\end{array}$ & $\begin{array}{l}\text { NA. Data for reference } \\
\text { material missed }\end{array}$ \\
\hline $\begin{array}{l}\text { Maros et al. } \\
\text { [52] }\end{array}$ & $\mathrm{Si}_{3} \mathrm{~N}_{4} / \mathrm{GNPS}$ & $1.5,4.4$ & $\begin{array}{l}\text { Ball-on- } \\
\text { disc }\end{array}$ & Dry & RT & $\begin{array}{c}\mathrm{Si}_{3} \mathrm{~N}_{4} \\
\mathrm{SiC}\end{array}$ & 40 & $\begin{array}{l}\downarrow 37 \%(1.5 \text { vol } \%) \\
\text { SiC ball }\end{array}$ & $\begin{array}{l}\uparrow 63 \%(4.4 \\
\text { vol) } \mathrm{Si}_{3} \mathrm{~N}_{4} \text { ball }\end{array}$ & $\begin{array}{l}\text { Tribofilm and } \\
\text { tribochemical corrosion }\end{array}$ \\
\hline Kim et al. & $\mathrm{Al}_{2} \mathrm{O}_{3} / \mathrm{GNPS}$ & $0.25,1.0$ & $\begin{array}{l}\text { Ball-on- } \\
\text { disc }\end{array}$ & Dry & RT & WC & 25 & $\downarrow 30 \%(1.0 \mathrm{vol} \%)$ & $\begin{array}{l}\uparrow 90 \%(1 \\
\text { yol } \%)\end{array}$ & $\begin{array}{l}\mathrm{GNPs} \text { layer on } \mathrm{Al}_{2} \mathrm{O}_{3} \text {, } \\
\text { grains, improved } \mathrm{K}_{\mathrm{IC}}\end{array}$ \\
\hline $\begin{array}{l}\text { Gutierrez et } \\
\text { al. [54] }\end{array}$ & $\mathrm{Al}_{2} \mathrm{O}_{3} / \mathrm{GOs}$ & 0.4 & $\begin{array}{l}\text { Ball-on- } \\
\text { plate }\end{array}$ & Dry & RT & $\mathrm{Al}_{2} \mathrm{O}_{3}$ & 20 & $\downarrow 7 \%$ & $\uparrow 50 \%$ & Graphene tribofilm \\
\hline $\begin{array}{l}\text { Yazdani et } \\
\text { al. [55] }\end{array}$ & $\mathrm{Al}_{2} \mathrm{O}_{3} / \mathrm{GNPS}$ & $0.9-8.7$ & $\begin{array}{l}\text { Ball-on- } \\
\text { disc }\end{array}$ & Dry & RT & $\mathrm{Si}_{3} \mathrm{~N}_{4}$ & $5-35$ & $\begin{array}{l}\downarrow 23 \%(0.9 \mathrm{vol} \%) \\
\text { at } 15 \mathrm{~N}\end{array}$ & $\begin{array}{l}\uparrow 70 \%(0.9 \\
\text { vol. } \%) \text { at } 35 \mathrm{~N}\end{array}$ & $\begin{array}{l}\text { Graphene tribofilm, } \\
\text { improved } \mathrm{K}_{\mathrm{IC}}\end{array}$ \\
\hline $\begin{array}{l}\text { Zhang et al. } \\
\text { [56] }\end{array}$ & $\mathrm{Al}_{2} \mathrm{O}_{3} / \mathrm{GNPS}$ & $0.5,5.0$ & $\begin{array}{l}\text { Ball-on- } \\
\text { disc }\end{array}$ & Dry & RT & $\mathrm{Al}_{2} \mathrm{O}_{3}$ & 40 & $\downarrow 33 \%$ (5 vol\%) & $\begin{array}{l}\uparrow 65 \%(0.5 \\
\text { vol. } \%)\end{array}$ & Graphene tribofilm \\
\hline $\begin{array}{l}\text { Llorente et } \\
\text { al. [57] }\end{array}$ & $\begin{array}{l}\mathrm{SiC} / \mathrm{GNPs} \\
\text { (GOs) }\end{array}$ & $\begin{array}{l}5.0-20.0 \\
(5.0)\end{array}$ & $\begin{array}{l}\text { Ball-on- } \\
\text { plate }\end{array}$ & Dry & RT & $\mathrm{Si}_{3} \mathrm{~N}_{4}$ & 5 & $\begin{array}{l}\downarrow 10 \%(5.0 \text { vol } \% \\
\text { GNPs) }\end{array}$ & $\begin{array}{l}\uparrow 72 \%(20.0 \\
\text { vol. } \% \text { GNPs })\end{array}$ & Graphene tribofilm \\
\hline $\begin{array}{l}\text { Porwal et } \\
\text { al. [58] }\end{array}$ & $\mathrm{SiO}_{2} / \mathrm{GNPs}$ & $2.0,5.0$ & $\begin{array}{l}\text { Ball-on- } \\
\text { disc }\end{array}$ & Dry & RT & $\begin{array}{c}\mathrm{Al}_{2} \mathrm{O}_{3} \\
\mathrm{BS}\end{array}$ & 5 & $\begin{array}{l}\downarrow 19 \%(5.0 \text { vol } \%) \\
\mathrm{Al}_{2} \mathrm{O}_{3} \text { ball }\end{array}$ & $\begin{array}{l}\uparrow 88 \%(5.0 \\
\text { vol) BS ball }\end{array}$ & $\begin{array}{l}\text { Graphene tribofilm, } \\
\text { improved } \mathrm{K}_{\mathrm{IC}}\end{array}$ \\
\hline $\begin{array}{l}\text { Li et al. } \\
\text { [59] }\end{array}$ & $\begin{array}{c}\text { Bioglass } / \mathrm{G} \\
\mathrm{O}\end{array}$ & $0.13-1.3$ & $\begin{array}{l}\text { Ball-on- } \\
\text { disc }\end{array}$ & Dry & RT & $\mathrm{Al}_{2} \mathrm{O}_{3}$ & 3 & $\downarrow 21 \%(0.64$ vol\%) & $\begin{array}{l}\uparrow 62 \%(0.64 \\
\text { vol. } \%)\end{array}$ & $\begin{array}{l}\text { Graphene tribofilm, } \\
\text { improved } \mathrm{K}_{\text {IC }}\end{array}$ \\
\hline $\begin{array}{l}\text { Li et al. } \\
{[60]}\end{array}$ & $\begin{array}{l}\mathrm{ZrO}_{2} / \mathrm{GNPs} \\
\text { coating }\end{array}$ & 2.7 & $\begin{array}{l}\text { Ball-on- } \\
\text { disc }\end{array}$ & Dry & RT & $\mathrm{Al}_{2} \mathrm{O}_{3}$ & $\begin{array}{l}10- \\
100\end{array}$ & $\downarrow 14 \%$ at $100 \mathrm{~N}$ & $\begin{array}{l}\uparrow 50 \% \text { at } 100 \\
\mathrm{~N}\end{array}$ & Graphene tribofilm \\
\hline $\begin{array}{l}\text { Gómez et } \\
\text { al. [61] }\end{array}$ & $\begin{array}{c}\text { YAS/GNPs } \\
\text { coating }\end{array}$ & $1.9,3.6$ & $\begin{array}{l}\text { Ball-on- } \\
\text { plate }\end{array}$ & Dry & RT & SS & $5-10$ & $\begin{array}{l}\downarrow 35 \%(3.6 \mathrm{vol} \%) \\
\text { at } 10 \mathrm{~N}\end{array}$ & $\begin{array}{l}\uparrow 65 \%(3.6 \\
\text { vol. } \%) \text { at } 10 \mathrm{~N}\end{array}$ & $\begin{array}{l}\text { Graphene tribofilm, } \\
\text { improved KIC }\end{array}$ \\
\hline $\begin{array}{l}\text { Xie et al. } \\
\text { [62] }\end{array}$ & $\begin{array}{l}\mathrm{CaSiO}_{3} / \mathrm{GN} \\
\text { Ps coating }\end{array}$ & $0.7-5.6$ & $\begin{array}{l}\text { Ball-on- } \\
\text { disc }\end{array}$ & Dry & RT & SS & 10 & $\begin{array}{l}\text { Lowest for } \\
\mathrm{CaSiO}_{3}\end{array}$ & $\begin{array}{l}\uparrow 95 \%(2.1 \\
\text { vol. } \%)\end{array}$ & $\begin{array}{l}\text { Bridging effects } \\
\text { between splats-particles }\end{array}$ \\
\hline
\end{tabular}

Figure 8 collects the maximum reduction of the friction coefficient $(\mu)$ from above studies due to the addition of graphene fillers (GNP or GO), in relation to corresponding reference monolithic materials. As it can be seen, most graphene composites experienced a reduction in $\mu$ within the $10-40 \%$ interval with the graphene fillers content, which ranged from 0.4 to 5.0 vol.\%. Scarce works observed a negligible $[48,58]$ or even a detrimental effect [62] on $\mu$. The plotted values were directly taken from the published works, although unfortunately in some cases certain doubts arise about those values, as the composites and the corresponding reference materials exhibited distinct microstructural characteristics (matrix grain size, crystalline and secondary phases, density, graphene dispersion degree, graphene damage after sintering...) that would affect to the tribological response, or simply some 
material information was missed. In spite of this, from Figure 8 it can be inferred that graphene (GNP or GO) act as self-lubricating solid, independently of the selected matrix. Besides, graphene contents $\leq 5$ vol.\% produce a substantial friction decrease.

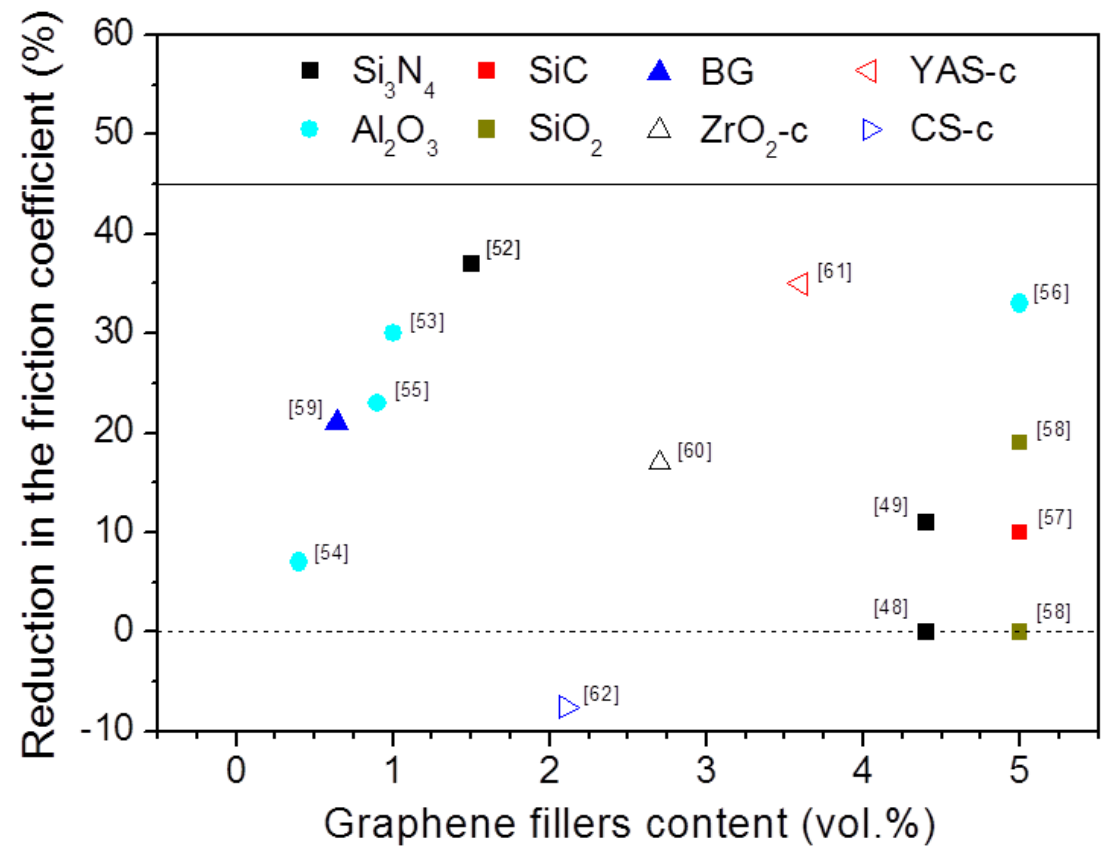

Figure 8. Maximum reduction in the friction coefficient $(\mu)$ versus the graphene fillers content (GNP or GO) considering all the reported studies on ceramic/graphene composites where the values for the reference material were also provided.

Concerning the wear resistance, a similar exercise has been done plotting the largest improvements reported for the different composites as a function of the graphene filler content (Figure 9). Generally, the addition of graphene in the form of GNP or GO led to at least a $50 \%$ improvement on the wear resistance of the reference material, reaching maximum increments close to $100 \%$. Focusing on $\mathrm{Al}_{2} \mathrm{O}_{3}$ - and $\mathrm{Si}_{3} \mathrm{~N}_{4}$-based composites, the 
materials more extensively investigated, some interesting results can be observed. In the case of $\mathrm{Al}_{2} \mathrm{O}_{3} /$ graphene composites, an excellent wear performance was reported for very low amounts (0.5-1.0 vol.\%) of GNP [53-56]; while for works where higher fillers contents (up to $\sim 10$ vol.\%) were introduced the wear resistance decreased due to the formation of GNP agglomerates during the processing of the composites [56] or to their poor mechanical properties [55]. However, to achieve the best results for $\mathrm{Si}_{3} \mathrm{~N}_{4} /$ graphene composites, larger GNP contents were required $(\sim 4.4$ vol.\%) $[48,49,52]$. Surprisingly, similar wear resistance improvements $(\sim 60 \%)$ were reported for all these studies despite different testing conditions were employed (dry testing at $5 \mathrm{~N} \mathrm{[48]} \mathrm{and} 40 \mathrm{~N}$ [52] or isooctane lubricated at $200 \mathrm{~N}$ [49]. Another interesting example is $\mathrm{SiC}$, one of the best ceramics for tribological applications. In this case, a continuous improvement on the wear resistance of $\mathrm{SiC}$ composites with the GNP content was reported [57], but GNP contents up to 20 vol.\% were needed for reaching considerably wear resistance increments (72\%).

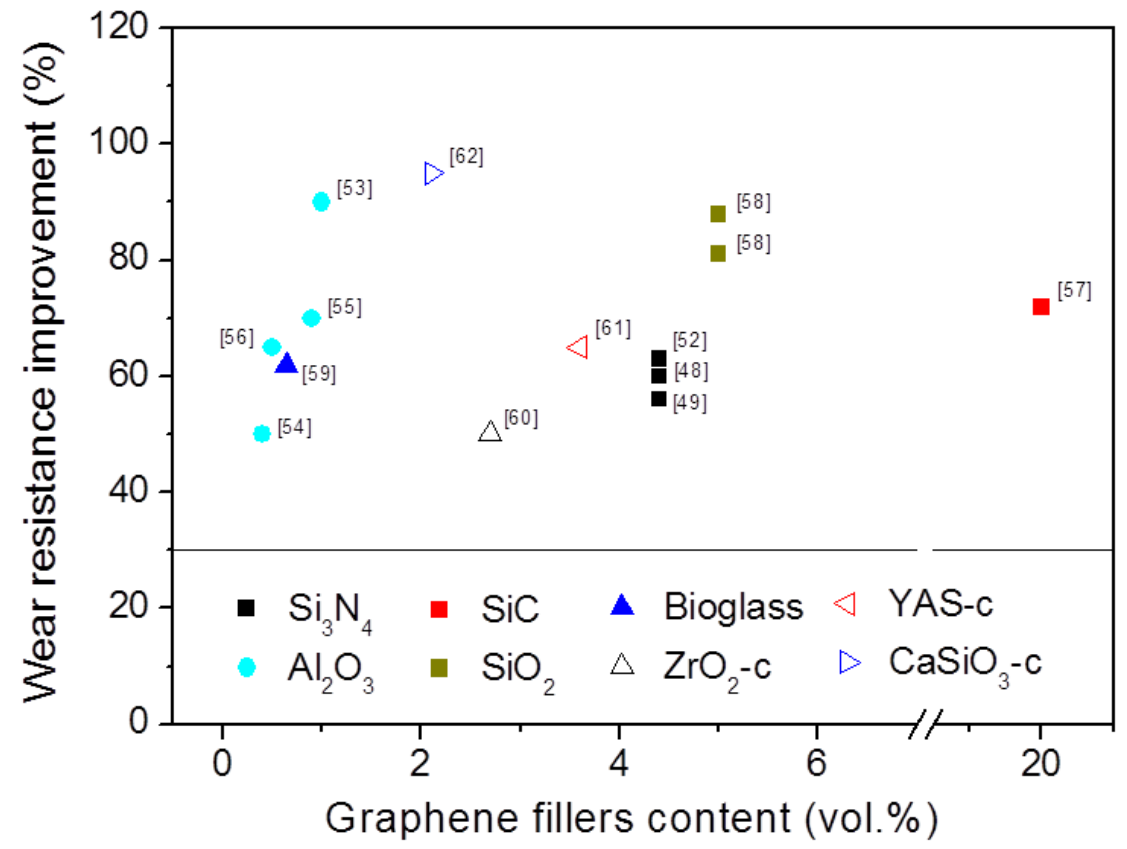


Figure 9. Maximum wear resistance improvements reported for ceramic/graphene composites as a function of the graphene filler content and type (GNP or GO). Only data for composites with available reference material are plotted.

The mechanism more widely accepted by the scientific community to explain the role played by graphene fillers on the enhanced tribological performance of ceramic/graphene composites is the formation of an adhered lubricating carbon-based tribofilm on the worn surface that protects against wear. This mechanism was first proposed by Belmonte et al. [49] and, in essence, it consists in the progressive pulling-out of the graphene flakes from the composite due to the sliding forces between the counterparts, leading to the formation of a wear protective film as the flakes are exfoliated and crushed. These authors analysed the composition of the wear debris on the wear scar by micro-Raman spectroscopy observing that increasing loads led to: i) an increment in the amount of few layer graphene, as a consequence of the GNP exfoliation, proved by the increase of the amount of features with high intensity ratio between 2D and G Raman bands (Figure 10 and ii) a larger damage (> intensity ratio between D and G Raman bands) suffered by the graphene structures during the crushing process that formed the carbon-based tribofilm.
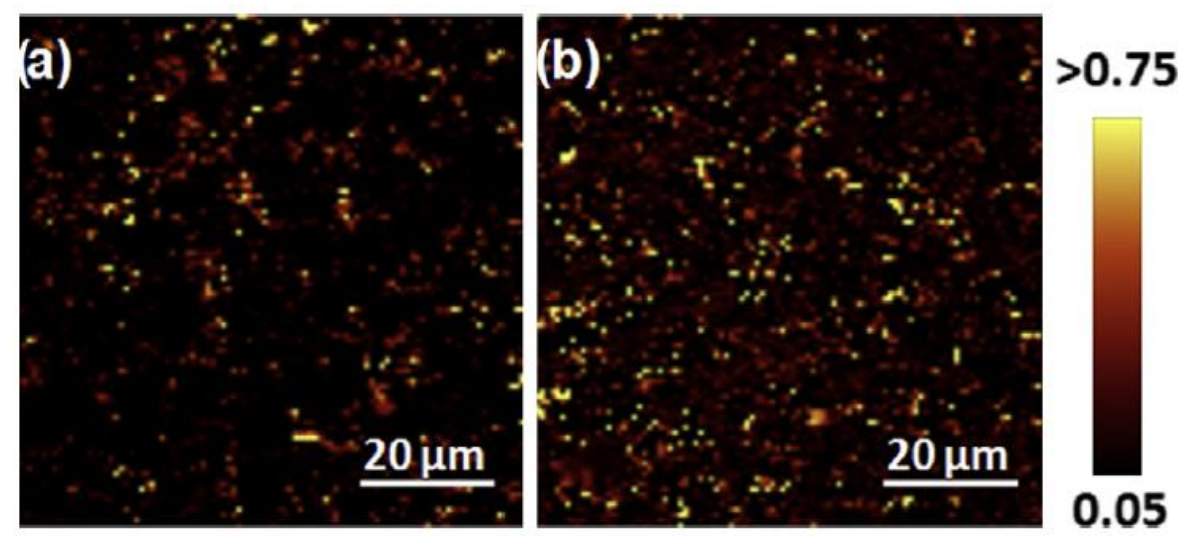
Figure 10. Raman maps of the worn $\mathrm{Si}_{3} \mathrm{~N}_{4} / 4.4$ vol.\% GNP composite surface tested at $50 \mathrm{~N}$ (a) and $200 \mathrm{~N}$ (b) under isooctane lubrication showing features (in yellow) associated to intense 2D/G bands ratio [49].

Further studies developed by other authors in different ceramic/graphene composites [5458, 60-61] confirmed the direct relationship between their improved tribological performances and the formation and stabilization of that carbon-based tribofilm (Figure 11 [56]. This process depends on the testing conditions and the microstructural and mechanical properties of the composites. In this way, higher applied loads provoked more extensive exfoliation and crushing of the pulled-out graphene stacks $[49,60]$; whereas larger graphene fillers contents improved the formation of lubricating islands until forming a continuous tribofilm $[57,58]$. The microstructure of the composites also influences the formation of the tribolayer. For instance, the pulling-out and exfoliation processes of the graphene flakes will be favoured if they are oriented with their basal plane parallel to the sliding motion, as it happens, for instance, when mechanical pressure assisted sintering techniques, such as the SPS, or thermal spraying techniques are employed to densify the composites or produce coatings, respectively. That orientation is also advantageous for improving the fracture toughness (see Section 1). In most of the tribological studies carried out in ceramic/graphene composites, graphene fillers present this orientation in respect to the sliding surface. 
Insufficient filler dispersion can produce a negative effect, as Zhang et al. [56] reported for $\mathrm{Al}_{2} \mathrm{O}_{3} / \mathrm{GNP}$ composites. In this study the graphene-based tribofilm became thicker and more lubricating with an increment in the GNP contents but, conversely, appeared less continuous due to GNP agglomeration that weaken the structure and induced fracture, losing the protection of the testing surface against wear. Finally, it is well known that during the sliding motion, especially under severe testing conditions, cyclic loading occurs promoting the development of surface and internal cracks in the material that may destabilize the adhered tribofilm. Therefore, under those conditions, an increment in the fracture toughness of the composites, as typically occurs when graphene fillers are added to ceramic matrices (see Section 1), would be very useful to limit the cracks propagation, diminishing the material removal by fracture $[53,58,61]$ and keeping the protective tribolfilm stable. Gomez et al. [61] schematic illustrated this process for YAS/GNP composite coatings (Figure 12), which is based on the progressive exfoliation of the GNP 
remaining over plateau-like features of the wear tracks (see SEM micrograph and corresponding Raman spectra in Figure 12) - retarding the matter removal-, and the role of the anisotropic mechanical properties of these coatings inducing crack arrest in the direction perpendicular to the surface and limiting wear damage inward.

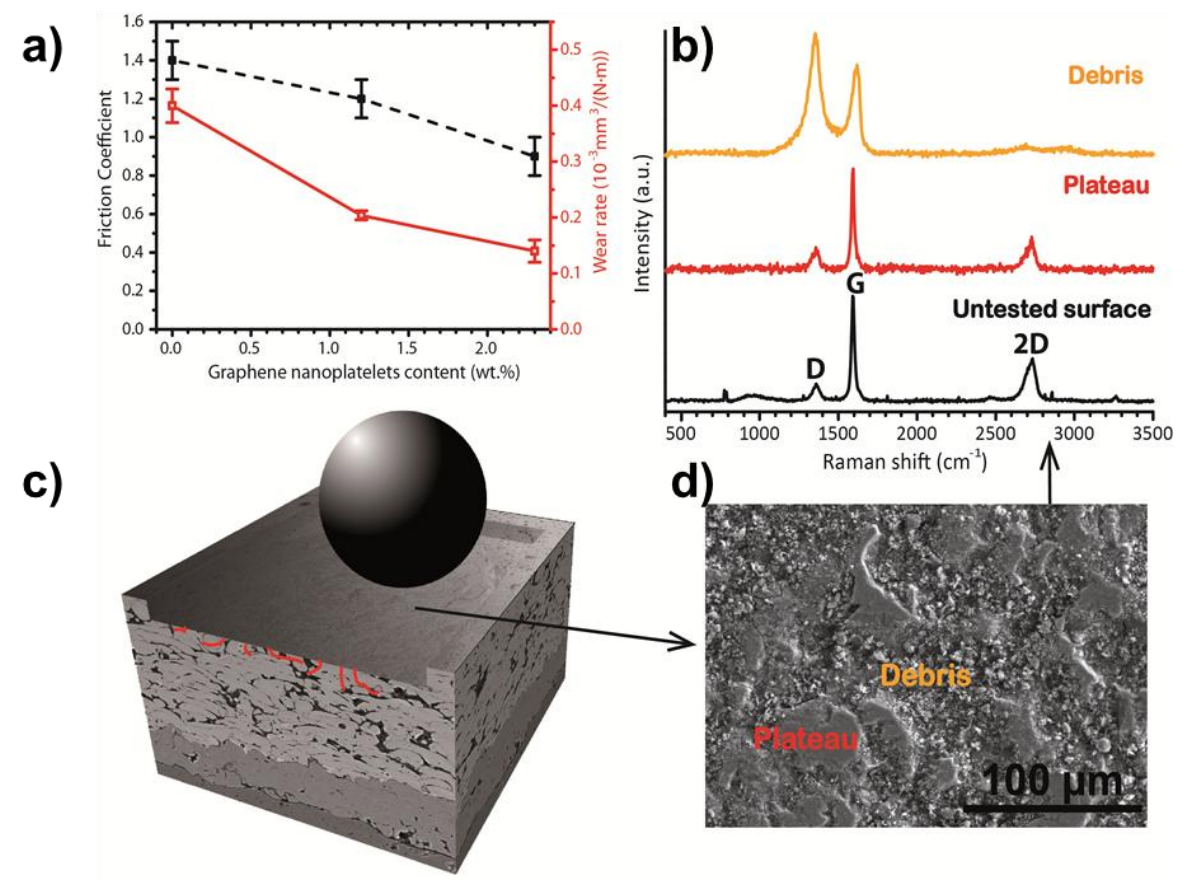

Figure 12. Tribological performance of YAS/GNP coatings [61]. a) Friction coefficient and wear rate versus GNP content for sliding tests at $5 \mathrm{~N}$ (black) and $10 \mathrm{~N}$ (red). b) MicroRaman spectra corresponding to debris and plateau of the wear scar (shown in figure d) and undamaged GNP. c) Schematic of the wear scars evolution where cracks are arrested by GNP in the direction perpendicular to the sliding surface. d) SEM micrograph of the wear scar.

Despite the formation of a protective carbon-based tribofilm has extensively been reported, it was not observed in some of the studies $[48,52]$, probably because other factors avoided 
its stabilization, such as a large porosity in the testing surface $[48,52]$ or the formation of tribofilms by tribochemical reaction of the counterparts [52] that competed against carbonbased ones.

It is important to remark that the development of a wear protecting tribofilm does not always mean lower friction, and the opposite. The formation of this tribofilm is an alive and cyclic process that can cover different stages (formation-stabilization-fracture-formation), inducing continuous changes in the film roughness, and hence, in the friction. In fact, Llorente et al. [57] found in SiC/GNP composites that despite the wear resistance considerably augmented (72\%) for 20 vol. $\%$ GNP composite due to the formation of a carbon-based tribofilm, the friction increased in about $23 \%$ because that tribofilm appeared cracked, roughening the surface.

Finally, the effect of the graphene source on the tribological properties has scarcely been investigated. Llorente et al. [57] compared the tribological response of GNP (10-20 nm thickness, $14 \mu \mathrm{m} x-y$ dimensions $)$, versus $\mathrm{rGO}(<5 \mathrm{~nm}$ thickness, $<5 \mu \mathrm{m}$ x-y dimensions $)$ for SiC composites containing 5 vol.\% of graphene fillers. While GNP reduced the $\mu$ in about $10 \%$, as compared to the monolithic material; it increased up to $23 \%$ when using rGO. In terms of wear, both composites were slightly more resistant than the reference ceramics, although rGO promoted a better response (13\%) than GNP (6\%). The authors justified the differences in the tribological behaviour because GNP were more easily removed, exfoliated and crushed than rGO, suffering a larger damage during the sliding motion and leading to a smoother and more compacted carbon-based tribofilm. Li et al. [60] investigated the tribological performance of $\mathrm{ZrO}_{2}$ coatings containing GNP $(5-20 \mathrm{~nm}$ thickness) or graphite (1-5 $\mu \mathrm{m}$ particle size) fillers. Both coatings presented better friction 
and wear resistance than the reference material, but distinct performance. In fact, $\mathrm{ZrO}_{2} / \mathrm{GNP}$ was the most wear resistant coating due to the formation of a continuous GNPrich amorphous transfer layer based on the mixture of $\mathrm{GNP}, \mathrm{ZrO}_{2}$, and $\mathrm{Al}_{2} \mathrm{O}_{3}$ (from the counterball) particles. However, $\mathrm{ZrO}_{2}$ /graphite did not exhibit a similar transfer layer and only a discontinuous carbon-rich film was observed, able to improve the lubrication but insufficient to protect against wear in the same way than $\mathrm{ZrO}_{2} / \mathrm{GNP}$ coatings.

\section{Electrical properties of ceramic/graphene composites}

One evident benefit of graphene-ceramic composites is the electrical functionality that these materials develop when the fillers are incipiently connected. It has also been proved that composites show anisotropic electrical conductivity $\left(\sigma_{\mathrm{e}}\right)$ due to preferential filler

orientation. Values for the $\sigma_{\mathrm{e}}{ }^{\text {in }} / \sigma_{\mathrm{e}}^{\text {cross }}$ ratio (in and cross exponents correspond to in-plane and cross-plane directions) between 2 and 25 have been reported for composites of $\mathrm{Al}_{2} \mathrm{O}_{3}$, $\mathrm{Si}_{3} \mathrm{~N}_{4}$, and $\mathrm{SiC}[9,15,63-65]$, which can be quantitatively predicted assuming a percolation-type models $[9,64,66]$. Most authors use the simplest percolation model for the fitting:

$\sigma_{l}=\sigma_{\mathrm{h}}\left(\mathrm{V}_{\mathrm{h}}-\mathrm{V}_{\mathrm{h}, \mathrm{c}}\right)^{\mathrm{t}}$

where, $\sigma_{1}$ and $\sigma_{\mathrm{h}}$ are the conductivities of the composite and the conducting phases, respectively, $\mathrm{V}_{\mathrm{h}}$ is the volume fraction of the conducting filler, $\mathrm{V}_{\mathrm{h}, \mathrm{c}}$ is the critical (percolation) volume fraction of the conducting phase, and t exponent is a parameter depends on the connectivity mode. This expression is only valid for $V_{h}>V_{c, h}$ near the percolation threshold. On the other, Ramirez et al [64] preferred predictions of the general 
effective media (GEM) equation for the electrical conductivity (Figure 13) because it gave more significant numerical solutions for in- and cross-plane $\sigma_{\mathrm{e}}$ of the graphene fillers and the t exponent, also being applicable to a broader compositional range close to the percolation limit. The critical GNP percolation volume fraction was found to be 7.3 and 8.7 vol. $\%$ for $\sigma_{\mathrm{e}}^{\text {in }}$ and $\sigma_{\mathrm{e}}^{\text {cross }}$, respectively, in very good agreement to the geometrical percolation threshold (equivalent to $V_{c, h}$ ) of randomly distributed overlapping ellipsoids with aspect ratio of 1:10 (similar to the GNP used in that work).

On the other hand, the electrical conductivity of SiC/GNP composites has been conveniently explained using the general rule of mixtures [65], attending to the measurable electrical transport of the matrix:

$\sigma^{\mathrm{n}}=\mathrm{fv} \sigma_{\mathrm{GNP}}^{\mathrm{n}}+(1-\mathrm{fv}) \sigma_{\mathrm{m}}^{\mathrm{n}}$

where $\sigma_{\mathrm{GNP}}$ and $\sigma_{\mathrm{m}}$ are the conductivities of GNP and the SiC matrix, respectively, and $\mathrm{f}_{\mathrm{v}}$ is the volume fraction of GNP. The exponent $\mathrm{n}$ accounts for the phase connectivity mode, being 1 for a parallel arrangement of both phases in the direction of the current flow, and -1 for a series arrangement. Data of $\mathrm{SiC}$ composites for both orientation - and fitting by eq. (2)- are plotted in Fig. 13 in comparison to results for $\mathrm{Si}_{3} \mathrm{~N}_{4}$ composites and the GEM prediction. 


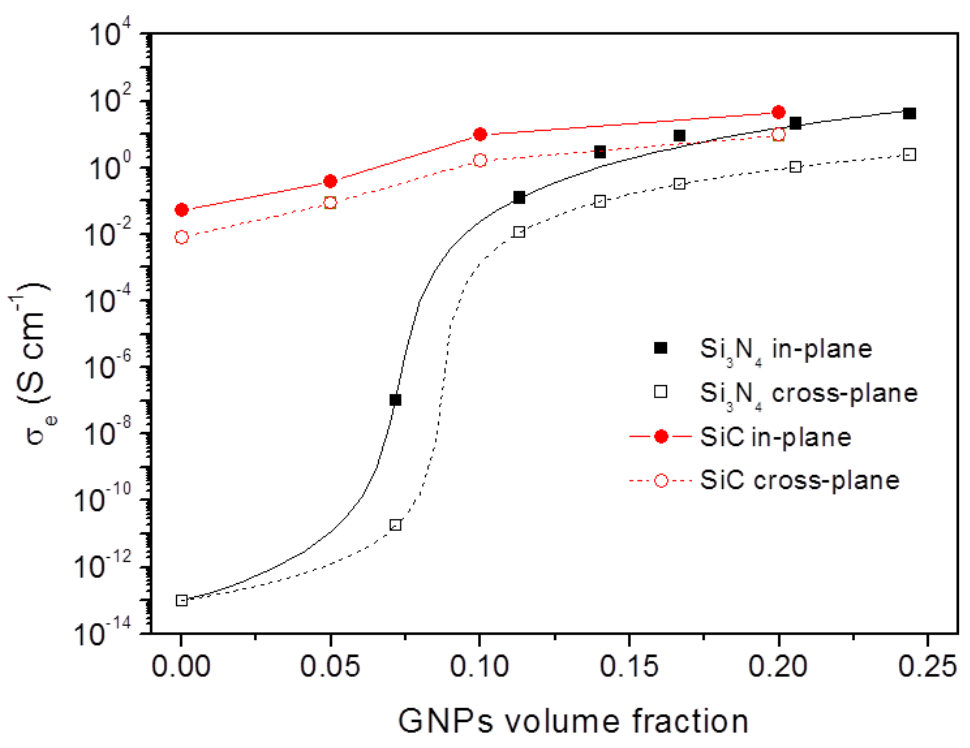

Figure 13. Electrical conductivity $\left(\sigma_{\mathrm{e}}\right)$ as a function of the volume fraction of GNP for $\mathrm{Si}_{3} \mathrm{~N}_{4}$ and $\mathrm{SiC}$ composites. Data for in-plane and cross- plane orientations replotted form references $[64,65]$. Lines correspond to the GEM and general rule of mixtures fittings for $\mathrm{Si}_{3} \mathrm{~N}_{4}$ and $\mathrm{SiC}$ composites, respectively.

The use of nano-scale scanning probes has shown particularly worthy for distinguishing the conductive graphene phase and determining its distribution. Localized conductance measurements by conductive scanning force microscopy (c-SFM) [67] also evidenced the pronounced anisotropy due to the visible orientation of the graphene sheets, but also owing to the high $\sigma_{\mathrm{e}}$ along the graphene plane and the expectedly much lower conductivity across the nanostructures (in a similar way to graphite) as shown in Figure 14. Much higher current is observed in the perpendicular orientation (respective to the SPS loading axis), which it has a higher weight of the graphene plane conductivity [67]. 

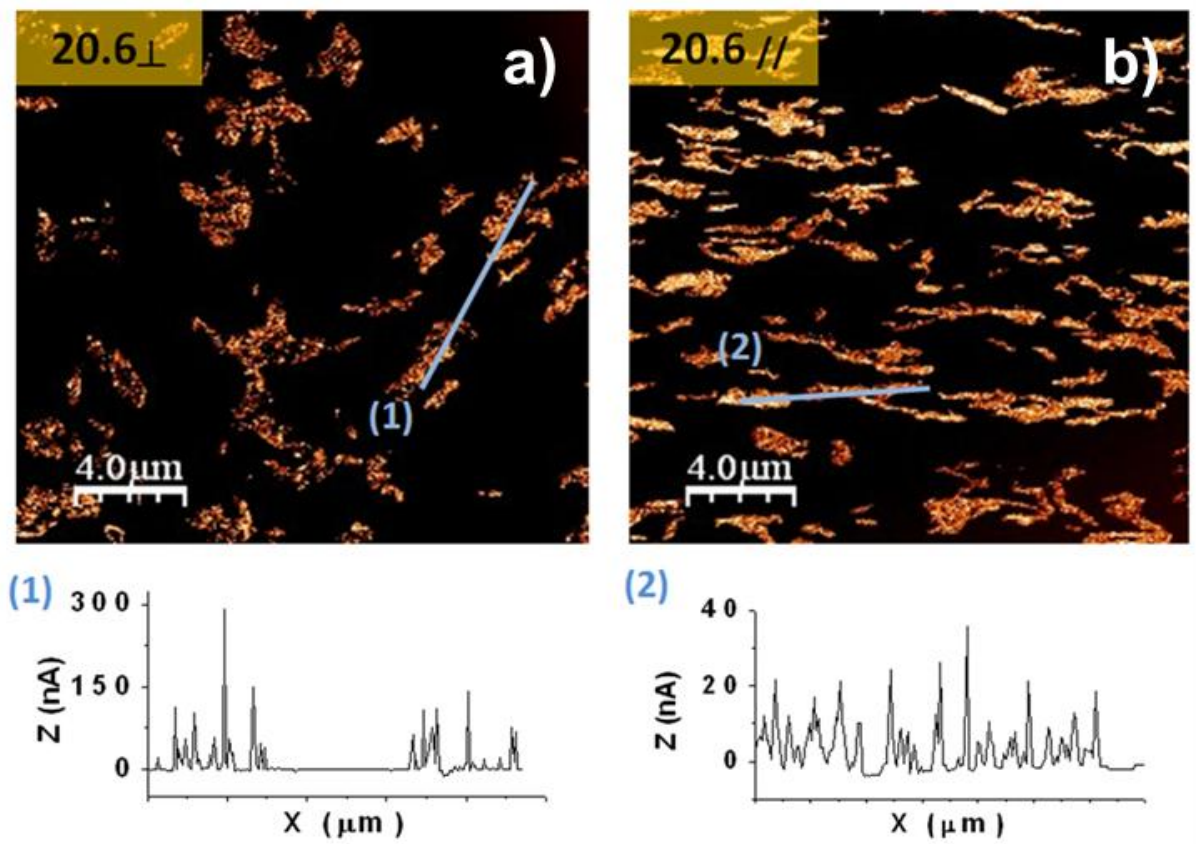

Figure 14. C-SFM current maps $\left(\mathrm{V}=2 \mathrm{~V}\right.$ ) of $\mathrm{Si}_{3} \mathrm{~N}_{4} / \mathrm{GNP}(20.6$ vol. $\%$ ) for (a) perpendicular and (b) parallel orientations to the SPS pressing axis. Corresponding current profiles along lines (1) and (2). Reprinted from reference [67].

It is illustrative to compare the electrical conductivity of some representative composites by plotting them together, as shown in Figure 15. Two distinct trends can be seen, one of percolating nature for dielectric matrices such as, $\mathrm{Si}_{3} \mathrm{~N}_{4}, \mathrm{Al}_{2} \mathrm{O}_{3}$ or $\mathrm{AlN}$, which show $\sigma_{\mathrm{e}}$ increases of several orders $(\geq 8)$ of magnitude with the volume fraction of the conducting phase; whereas for conducting matrices, namely $\mathrm{SiC}$ and $\mathrm{B}_{4} \mathrm{C}$, comparatively moderate increases (3-4 orders of magnitude) are perceived with the volume fraction. The data for the YSZ composite, which pertains to the last category, in fact shows a behaviour diverging form the rest of the matrices (Fig. 15). 
Figure 15. Electrical conductivity $\left(\sigma_{\mathrm{e}}\right)$ perpendicular to the pressing axis data vs volume content of the conducting phase for the gamut of indicated composites. Data correspond to the references shown in brackets.

Differences in the percolation limit for these composites are attributable to distinct aspect ratios of the fillers, as theory predicts and it has been experimentally shown by employing highly exfoliated $\mathrm{GO}$ in $\mathrm{Al}_{2} \mathrm{O}_{3}$ through a colloidal route [66], which reduced percolation limit to 0.38 vol.\%, or by using graphene nanoribbons -chemically open carbon nanotubesin $\mathrm{Si}_{3} \mathrm{~N}_{4}$ that comparatively to other fillers reduced the limit for electrical conduction.

Studies on the change of $\sigma_{\mathrm{e}}$ with temperature are scarce, although they help to identify conduction mechanisms. An increase of $\sigma_{\mathrm{e}}$ with temperature is normally observed for these materials. In particular, for $\mathrm{Si}_{3} \mathrm{~N}_{4}$ and $\mathrm{SiC}$ composites the in-plane conductivity has been 
explained by the $2 \mathrm{D}$ variable range hoping (2D-VRH) mechanism, which is characteristic of graphene with defective islands, as it happens in the rGO monolayer [64, 65].

The occurrence of thermopower effect has been demonstrated in $\mathrm{YSZ}$ and $\mathrm{Si}_{3} \mathrm{~N}_{4}$ ceramics with graphene fillers, reporting maximum Seebeck coefficient, $\mathrm{S}$, around $-25 \mu \mathrm{V} \cdot \mathrm{K}^{-1}$ for both composites with $\mathrm{rGO}$ fillers $[71,72]$. Conversely, $\mathrm{Si}_{3} \mathrm{~N}_{4} / \mathrm{GNP}$ composites showed $\mathrm{S}$ values of $+5 \mu \mathrm{V} \cdot \mathrm{K}^{-1}$, where the opposite sings indicate that electric carriers were electrons for the rGO composites and holes for the GNP. Surprisingly, Fan et al. [66] observed this change in the current carrier sign within same composite $\left(\mathrm{Al}_{2} \mathrm{O}_{3} / \mathrm{rGO}\right)$ when increasing the volume fraction of rGO. The thermopower produced a thermoelectric effect in above composites although the referred figures of merit $\left(\mathrm{Z}<10^{-4}\right)$ were well below those sought for practical uses.

\section{Thermal conductivity of ceramic/graphene composites}

The excellent thermal properties of graphene $[73,74]$ foster the use of GNP as an interesting filler for the thermal functionalization of ceramic matrices. Although comparatively less investigated than mechanical, tribological and electrical properties, the effect of GNP and GO on the thermal behaviour of ceramics has been studied for several composites such as $\mathrm{Al}_{2} \mathrm{O}_{3}$ [75, 76], $\mathrm{Si}_{3} \mathrm{~N}_{4}$ [51, 77], $\mathrm{AlN}[68,78], \mathrm{ZrO}_{2}$ [21], $\mathrm{B}_{4} \mathrm{C}$ [44, 79] and $\mathrm{SiC}[80,81]$. As it will be described below, conversely to the common thinking, the effect of adding graphene to ceramic matrices is not universal and we can distinguish diverse thermal behaviours for ceramic/graphene composites depending on the matrix, the nanoplatelets orientation within the matrix and type of carbon nanostructure. 
The unique common feature of the thermal behaviour of ceramic/graphene composites is the development of thermal anisotropy when using pressure-assisted processes as in the case of SPS or HP [51, 75, 77, 81, 82] because of the strong orientation of the carbon nanostructures. In this way, the thermal conductivity $(\mathrm{K})$ of the composites is either enhanced or just slightly reduced with increasing amounts of GNP in the direction defined by the graphene basal plane ( $\perp$, perpendicularly to the pressing axis), while it is strongly impaired in the parallel $(\|)$ direction for all the SPSed studied materials (Figure 16). As it is shown in Figure 16a, the strongest reductions in $\mathrm{K}_{\|}$are observed for AlN/graphene composites $(68,78,83)$, which range between 55 and $85 \%$. For $\mathrm{Al}_{2} \mathrm{O}_{3} / \mathrm{GNP}$ composites (with up to 20 vol.-\% GNP) processed by HP [75], $\mathrm{K}_{\|}$decreases of $40-50 \%$ with increasing GNP content were observed, although results on thermal transport of SPSed $\mathrm{Al}_{2} \mathrm{O}_{3} / \mathrm{GNP}$ specimens by same authors were not conclusive. On the other hand, reductions on $\mathrm{K}_{\|}$were always below $30 \%$ for $\mathrm{Si}_{3} \mathrm{~N}_{4}[77,84], \mathrm{B}_{4} \mathrm{C}$ [82] and $\mathrm{SiC}$ [81] composites.

Conversely, more contradictory data are reported for the thermal conductivity along the inplane $\left(\mathrm{K}_{\perp}\right)$ direction (Figure $16 \mathrm{~b}$ ). Very strong increase of $\mathrm{K}_{\perp}$ with the GNP content (up to $90 \%$ for a $16.7 \mathrm{vol} . \%$ GNP composite) was reported [77] for liquid phase SPSed $\mathrm{Si}_{3} \mathrm{~N}_{4} / \mathrm{GNP}$ composites. Special care was paid to compare materials with the same amount of $\beta-\mathrm{Si}_{3} \mathrm{~N}_{4}$ phase content (around $77 \%$ ) because of the strong dependence of the matrix thermal conductivity with this parameter. A posterior study [84] reported significantly lower increases in $\mathrm{K}_{\perp}$ (40\% for 14 vol.\% of GNP) with GNP content for liquid phase HPed $\mathrm{Si}_{3} \mathrm{~N}_{4} / \mathrm{GNP}$ containing similar amount of oxide additives; these materials had higher $\beta$ $\mathrm{Si}_{3} \mathrm{~N}_{4}$ contents and consequently higher matrix thermal conductivity $\left(\mathrm{K}_{\|} \sim 28 \mathrm{~W} \cdot \mathrm{m}^{-1} \mathrm{~K}^{-1}\right.$ and $\mathrm{K}^{\perp}=42 \mathrm{~W} \cdot \mathrm{m}^{-1} \mathrm{~K}^{-1}$, for the monolithic $\mathrm{Si}_{3} \mathrm{~N}_{4}$ ) than the SPSed composites reported by 
Miranzo et al. [77] $\left(\mathrm{K}_{\|} \sim 18 \mathrm{~W} \cdot \mathrm{m}^{-1} \mathrm{~K}^{-1}\right.$ and $\mathrm{K}_{\perp}=20 \mathrm{~W} \cdot \mathrm{m}^{-1} \mathrm{~K}^{-1}$ for the matrix $)$. Although grain size data were not included for the former composites, it is also known that HPed materials usually develop higher grain sizes than the comparable SPSed materials, thus affecting the thermal conductivity of $\mathrm{Si}_{3} \mathrm{~N}_{4}$ [85]. Both studies revealed significant level of anisotropy for $\mathrm{Si}_{3} \mathrm{~N}_{4} / \mathrm{GNP}$ composites, with $\mathrm{K}_{\perp} / \mathrm{K}_{\|}$values of $\sim 3$ (Figure $16 \mathrm{c}$ ).
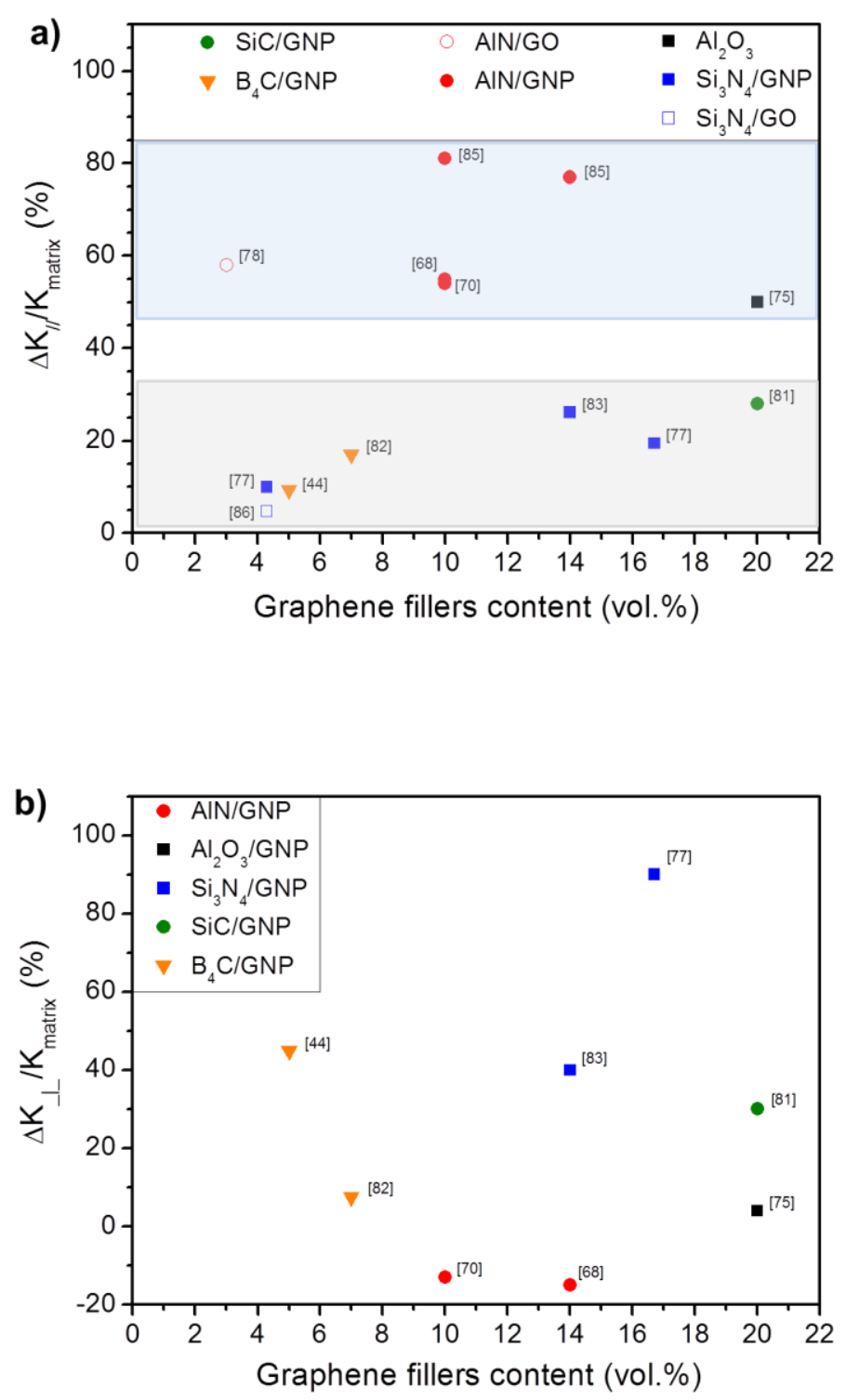


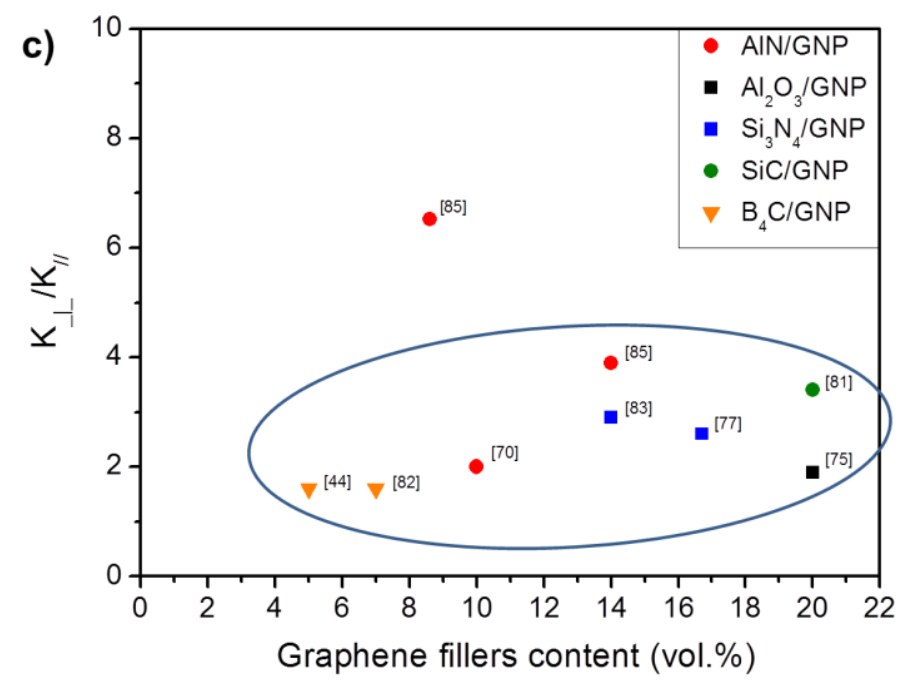

Figure 16. (a) Relative thermal conductivity reduction in the direction parallel to the pressing axis $\left(\Delta \mathrm{K}_{/ /} / \mathrm{K}_{\text {matrix }}\right)$, (b) variation in the perpendicular direction $\left(\Delta \mathrm{K}_{\perp} / \mathrm{K}_{\text {matrix }}\right)$ and (c) corresponding $\mathrm{K}_{\perp} / \mathrm{K}_{\|}$ratio in HPed and SPSed ceramic/graphene composites (numbers in brackets show the corresponding references). Colours designate different matrices whereas full and empty symbols indicate the use of GNP and rGO, respectively. Top value from each study is considered in that graph, except few additional points for comparison purposes in the text.

$\mathrm{K}_{\perp}$ increases above $30 \%$ were also stated for $\mathrm{B}_{4} \mathrm{C} / \mathrm{GNP}[44,81]$ composites (Figure 16b), while irrelevant rises and even decreases on $\mathrm{K}_{\perp}$ were reported for $\mathrm{Al}_{2} \mathrm{O}_{3} / \mathrm{GNP}$ [75] and AlN/GNP [70, 83] composites, respectively. This decrease in thermal conduction for the inplane direction has been explained in a recent work by the existence of matrix/graphene interfacial thermal resistances [70]. From Figure 16c, increasing $\mathrm{K}_{\perp} / \mathrm{K}_{\|}$values with the GNP content (within the range of $\sim 2.0-4.0$ ) are reported for ceramic/graphene composites 
containing up to 20 vol. $\%$ of GNP. The exception is the $\mathrm{K}_{\perp} / \mathrm{K}_{\|}$value of 6.5 reported for HPed AlN composite with 8.6 vol.\% of GNP, but this specially high $\mathrm{K}_{\perp} / \mathrm{K}_{\|}$would require a deeper analysis as composite with 14 vol. \% GNP from same study presented a significantly lower value of 3.9 [83].

A different situation arises when GNP are not oriented but uniformly distributed within the matrix. In this case, there are only two studies and they report contradictory data. The thermal conductivity of an isotropic porous graphene (11 wt.\%)/nanostructured $\mathrm{Al}_{2} \mathrm{O}_{3}$ composite decreased from 0.25 (bare alumina) to $0.13 \mathrm{~W} \cdot \mathrm{m}^{-1} \cdot \mathrm{K}^{-1}$ probably due to the lower densification of the $\mathrm{Al}_{2} \mathrm{O}_{3}$ /graphene composite [76]. In contrast, Li et al [80] reported an increase of $28 \%$ in $\mathrm{K}$ for a SiC/GNP composite with 2.8 vol.\% of isotropic distributed GNP.

Finally, contradictory data are found for GO fillers. Very low reduction (5\%) in thermal conductivity in the direction parallel is reported (Figure 16a) for a $\mathrm{Si}_{3} \mathrm{~N}_{4}$ with 4.3 vol.\% rGO [86] compared to similar GNP contents. This is not the case for AlN/rGO composites where a very strong decrease (58\%) is observed for only 3 vol.\%, although in this case density decreased compared to the bare material [78]. Moreover, even a slight increase of $12 \%$ is reported for the thermal diffusivity of SPSed $\mathrm{ZrO}_{2} / \mathrm{rGO}$ (3-4 vol. \%) composites [21]. These apparently inconsistent results can be associated to the wide range of GO fillers characteristics and points to the necessity of deeper systematic studies for rGO containing composites.

Up to now, there are scarce models explaining the thermal behaviour of ceramic/graphene composites. Considering the elevated degree of anisotropy of ceramic/graphene composites with highly oriented 2D fillers (sintered by HPed and SPSed), a simple model of thermal 
resistances has been proposed for the interpretation of the in-plane and cross-plane conductivities $[81,86]$. In this model, the structure of the ceramic/GNP composites was regarded as two distinct phases, the ceramic matrix and the dispersed GNP, arranged as series or parallel thermal resistances for the heat flow when measuring in the parallel and perpendicular directions, respectively. In that model, the interfacial thermal barrier resistance between GNP and the ceramic matrix is assumed to be included in the deduced $\mathrm{K}_{\mathrm{GNP}}$ value. The curves from the proposed model are displayed in Figure 17 for $\mathrm{SiC}$ showing an adequate fitting for $\mathrm{K}_{\perp \mathrm{GNP}}=152 \mathrm{~W} \cdot \mathrm{m}^{-1} \cdot \mathrm{K}^{-1}$ and $\mathrm{K}_{/ / \mathrm{GNP}}=9.9 \mathrm{~W} \cdot \mathrm{m}^{-1} \cdot \mathrm{K}^{-1}[81]$. If we applied this simple model to thermal conductivity data published for different composites and plot them together (Figure 18), we observe a reasonable agreement when using $\mathrm{K}_{\perp \mathrm{GNP}}=152 \mathrm{~W} \cdot \mathrm{m}^{-1} \cdot \mathrm{K}^{-1}$ and $\mathrm{K}_{/ / \mathrm{GNP}}$ between 9.9 and $4.5 \mathrm{~W} \cdot \mathrm{m}^{-1} \cdot \mathrm{K}^{-1}$.

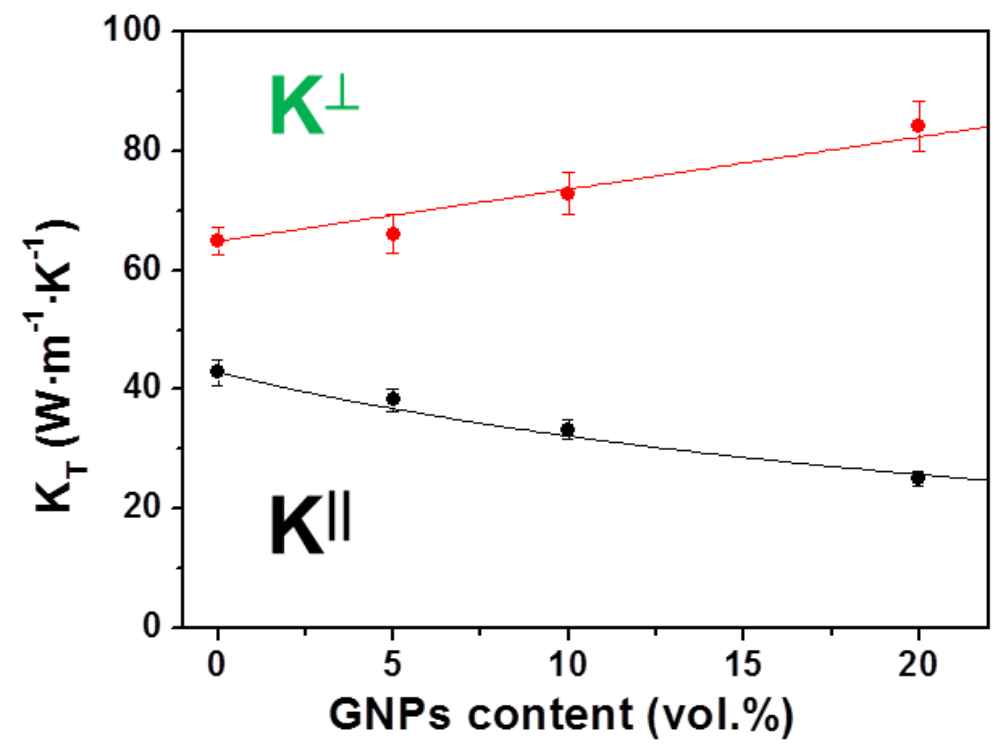

Figure 17. Room temperature $\mathrm{K}$ values for the different composites as a function of the GNP content considering the cross-plane $\left(\mathrm{K}_{\|}\right)$and in-plane $\left(\mathrm{K}_{\perp}\right)$ directions. Errors represent the estimated accuracy of the laser flash technique, being $\sim 5 \%$ for parallel diffusivity data 
and the standard deviation of the values for the perpendicular diffusivity. Lines are the predictions from the resistors model [81].

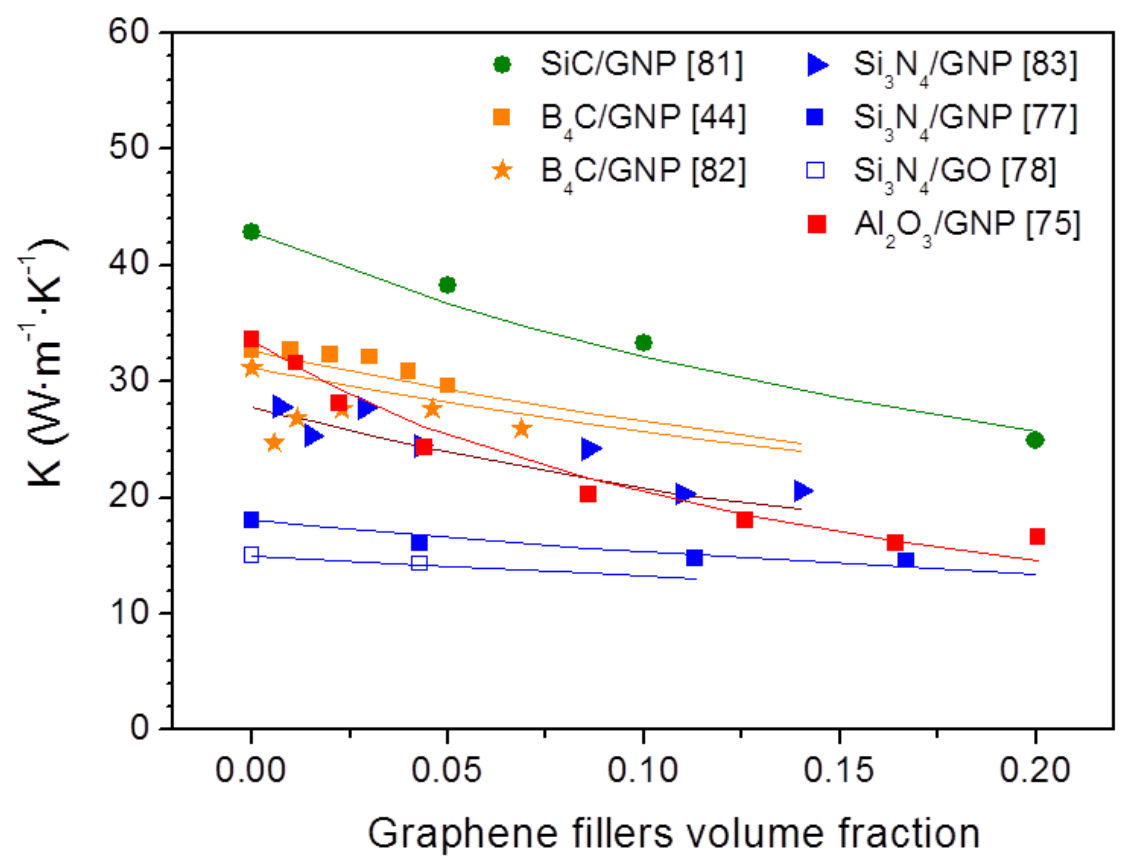

Figure 18. Thermal conductivity in the direction parallel to the pressing axis as a function of the graphene filler content for different composites, using referred published data.

GNP within the ceramic matrices show a thermal behaviour similar to that of graphite instead of graphene $[73,74]$ as the value deduced for $\mathrm{K}_{\perp \mathrm{GNP}}$ is almost one order of magnitude lower than that of highly oriented pyrolytic graphite $\left(\sim 2000 \mathrm{~W} \cdot \mathrm{m}^{-1} \cdot \mathrm{K}^{-1}\right.$ in the inplane direction) but is close to that of polycrystalline graphite $\left(\sim 200 \mathrm{~W} \cdot \mathrm{m}^{-1} \cdot \mathrm{K}^{-1}\right)$ at room temperature, as seen in Figure 19a). The slightly lower value deduced for GNP can be explained because of the presence of defects, being twisted and bent within the composite. The values of $\mathrm{K}_{\perp \mathrm{GNP}}$ and $\mathrm{K}_{/ / \mathrm{GNP}}$ should depend on the crystallinity and size of the used 
nanoplatelets as well as on the GNP/matrix interface. In nanostructures, $\mathrm{K}$ is reduced by scattering from boundaries, which can be evaluated as [73]:

$1 / \tau_{B}=(v / D)((1-p) /(1+p))$

where $\tau_{B}$ is the phonon lifetime, $D$ is the nanostructure size and $p$ is the specularity parameter defined as a probability of specular scattering at the boundary. In this way, when the phonon-boundary scattering is dominant, $\mathrm{K}$ scales with $\mathrm{D}$ :

$K \sim C_{p} v D$

Here $C_{p}$ is the specific heat and $v$ is phonon group velocity. In nanostructures with $\mathrm{D}<<\Lambda$, where $\Lambda$ is the phonon mean free path, phonon dispersion can undergo modifications owing to confinement resulting in changes in $v$ and more complicated size dependence.

Furthermore, thermal conductivity values obtained from the in-plane fittings for GNP in ceramic/graphene composites are within those reported for encased graphene as summarized in Figure 19b [73]. Here we can observed that, despite the high roomtemperature value for freely suspended graphene samples, the in-plane thermal conductivity of graphene supported by $\mathrm{SiO}_{2}$ was $\sim 600 \mathrm{~W} \cdot \mathrm{m}^{-1} \cdot \mathrm{K}^{-1}$ and that of $\mathrm{SiO}_{2}$-encased graphene was $\sim 160 \mathrm{~W} \cdot \mathrm{m}^{-1} \cdot \mathrm{K}^{-1}$. This behaviour is expected, considering that phonon propagation in graphene sheets is very sensitive to surface or edge perturbations. 

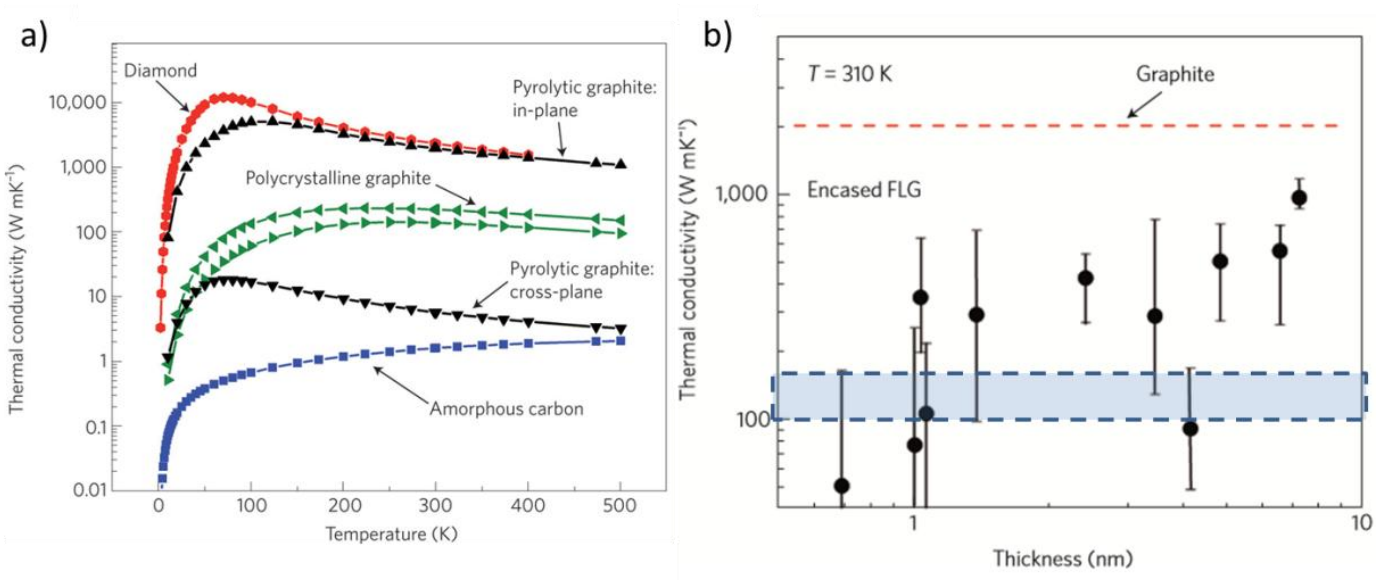

Figure 19. a) Thermal conductivity of bulk carbon allotropes as a function of $T$. b) Measured $K$ of encased few layer graphene (FLG) as a function of thickness, reprinted with permission from Balandin [73] Copyright 2011 Nature Publishing Group. Shadow area in Figure $19 \mathrm{~b}$ includes range of $\mathrm{K}_{\perp \mathrm{GNP}}$ values deduced from the resistor model.

On the other hand, the deduced $\mathrm{K}_{/ / \mathrm{GNP}}$ values $4.5-10 \mathrm{~W} \cdot \mathrm{m}^{-1} \cdot \mathrm{K}^{-1}$ are close to the crossplane conductivity of the highly oriented pyrolytic graphite $\left(\sim 6 \mathrm{~W} \cdot \mathrm{m}^{-1} \cdot \mathrm{K}^{-1}\right)$. Therefore, the reduced cross-plane thermal conductivity can be mainly attributed to the much lower intrinsic conductivity of the added GNP in the c-axis and to some contribution of the thermal resistance of the GNP-matrix interfaces. These interfaces play a key role also on the in-plane thermal conductivity explaining the reduced values reported for some matrices like $\mathrm{Al}_{2} \mathrm{O}_{3}$ or $\mathrm{AlN}$.

In a recent paper by some of the present authors [70], the thermal behaviour of AlN/GNP materials in both directions has been conveniently reproduced by introducing in the effective media thermal conductivity model a contact thermal conductance $\left(\mathrm{h}_{\mathrm{c}}\right)$ of $\sim 3 \times 10^{8}$ $\mathrm{W} \mathrm{m} \mathrm{m}^{-2} \mathrm{~K}^{-1}$ at the AlN/GNP interface. This value agrees with calculations done for the 
interface thermal conductance of graphene- $\mathrm{SiO}_{2}$ coupling and is, therefore, the effect of the graphene thermal coupling with a substrate owing to the differences in the phonon density of states [73].

\section{New graphene-based ceramic structures}

\subsection{Layered ceramic/graphene materials}

Layered ceramics were first proposed by Clegg et al. [87] more than two decades ago as an innovative approach for enhancing the mechanical performance of monolithic ceramics and composites. This approach was bioinspired by numerous layered examples presented in the nature, in particular, bones, shells and wood [88]. Despite the initial goal of layered ceramics was to increase the strength and toughness, these materials could also be developed to enhance the directional transport properties [89] for promising applications linked, for instance, to thermal or electromagnetic interference shields.

As it has been pointed out in the previous sections, graphene fillers are able to significantly improve most of the properties of bulk ceramics. Therefore, we are now in a position to take a challenged step forward for tailoring new materials based on the layered concept, this time including graphene into the ceramic structure. At the present, very few works on ceramic/graphene layered materials have been reported [90-94], which could be classified in two different categories according to their processing approaches. In the first approach, each layer, or some of them, is formed by a bulk ceramic/GO composite [90, 93, 94] and, hence, will be labelled as "layered composites". The second approach consisted in 
alternating a ceramic layer and a graphene film [91, 92], thus being labelled as "layered ceramic/graphene materials". Table 2 summarizes the works reported for both approaches.

Table 2. Summary of the works reported on "layered composites" (LC) and "layered ceramic/graphene materials" (LCGM) approaches.

\begin{tabular}{|c|c|c|c|}
\hline Reference & Approach & Material & Properties of the layered material \\
\hline $\begin{array}{l}\text { Rincon et } \\
\text { al. [90] }\end{array}$ & LC & $\begin{array}{l}\text { A/AZ/AZGO }(2 \text { vol. } \% \text { GO }) \\
18 \text { layers of } \sim 100 \mu \mathrm{m} \text { each }\end{array}$ & $\begin{array}{l}\text { Electrical resistance of the AZGO layers much lower than for A and } \\
\mathrm{AZ} \text { ones }\end{array}$ \\
\hline $\begin{array}{l}\text { Rincon et } \\
\text { al. [93] }\end{array}$ & LC & $\begin{array}{c}\text { 8YSZ/GOs coated } 8 \mathrm{YSZ} \text { (vol. ratio } 30: 70) \\
15-20 \text { layers: } 8 \mathrm{YSZ}(160-180 \mu \mathrm{m}) \text {, GOs coating of } 8 \mu \mathrm{m}\end{array}$ & $\begin{array}{l}\text { Cracks arrested in the cross-sectional direction once reached GOs- } \\
\text { rich layers }\end{array}$ \\
\hline $\begin{array}{l}\text { An et al. } \\
{[94]}\end{array}$ & LC & $\begin{array}{c}\mathrm{ZrB} 2 / \mathrm{GOs}(5,30 \text { vol. \% GOs) } \\
\mathrm{ZrB}_{2}-\mathrm{SiC} / \mathrm{GOs}(5,30 \text { vol. } \% \text { GOs })\end{array}$ & $\mathrm{ZrB}_{2} / \mathrm{GOs}$ : increment in $\sigma_{\mathrm{f}}$ and $\mathrm{KIC}$ of $28 \%$ and $223 \%$ respectively \\
\hline $\begin{array}{l}\text { Belmonte } \\
\text { el at. [91] }\end{array}$ & LCGM & $\begin{array}{c}\mathrm{Si}_{3} \mathrm{~N}_{4} / \mathrm{GO} \text { (total rGOs content }=0.03 \text { vol \%) } \\
6 \mathrm{Si}_{3} \mathrm{~N}_{4} \text { layers }(400 \mu \mathrm{m} \text { each), } 5 \mathrm{GO} \text { films }(200 \mathrm{~nm} \text { each })\end{array}$ & $\begin{array}{l}\text { Increased } \sigma_{e} \text { of up to } 16 \text { orders of magnitude in the in-plane direction } \\
\text { and } 25 \% \text { faster heat flow. KIc increase of } 15 \% \text { (SCF) and } 42 \% \text { (IF) }\end{array}$ \\
\hline
\end{tabular}

Within the "layered composites" group, Rincon et al. [90, 93] reported the fabrication by aqueous tape casting and SPS of two different kinds of materials. In the first work, green tapes of $\mathrm{Al}_{2} \mathrm{O}_{3}(\mathrm{~A}), \mathrm{Al}_{2} \mathrm{O}_{3} / 5$ vol.\% of $3 \mathrm{Y}-\mathrm{TZP}(\mathrm{AZ})$, and $\mathrm{Al}_{2} \mathrm{O}_{3} / 5$ vol.\% of $3 \mathrm{Y}-\mathrm{TZP} / 2$ vol.\% of GO (AZGO) were individually obtained. Afterwards, tapes were cut into $20 \mathrm{~mm}$ diameter discs and then laminated in an A/AZ/AZGO sequence applying a small pressure and using few drops of water as gluing agent between the discs. A symmetric stack with 9 layers were first processed and 2 stacks were piled up and SPSed at $1400{ }^{\circ} \mathrm{C}$. A good cohesion between sintered layers was observed, the ceramic layers (A and AZ) being dense while those containing GO (AZGO) exhibited considerably higher porosity. The authors confirmed that the electrical resistance of the AZGO layers was much lower than that of the A and AZ ones. In a later work [93], the-authors tape casted 8YSZ layers and some of them were coated with $8 \mathrm{YSZ} / \mathrm{GO}$ composition by dipping a rectangular 8YSZ substrate into an 8YSZ/GO (volume ratio of 30:70) suspension. By alternating uncoated and coated layers, two different layered configurations were developed: one containing 5 stacks of 3 layers 
(Figure 20) and another one formed by 4 stacks of 5 layers. After the SPS process at 1400 ${ }^{\circ} \mathrm{C}$, the thickness of the $8 \mathrm{YSZ}$ and $8 \mathrm{YSZ} / \mathrm{GO}$ layers were $160-180 \mu \mathrm{m}$ and $8 \mu \mathrm{m}$, respectively. The authors found, by performing indentation tests in the 8YSZ ceramic layers that cracks propagated in the horizontal direction within the uncoated layer but were arrested in the cross-sectional direction once reached GO-rich layers. Unfortunately, despite this promising response, mechanical performance of the whole stacked layered composite was not provided. In both published works by this group information of the GO reduction was not reported.

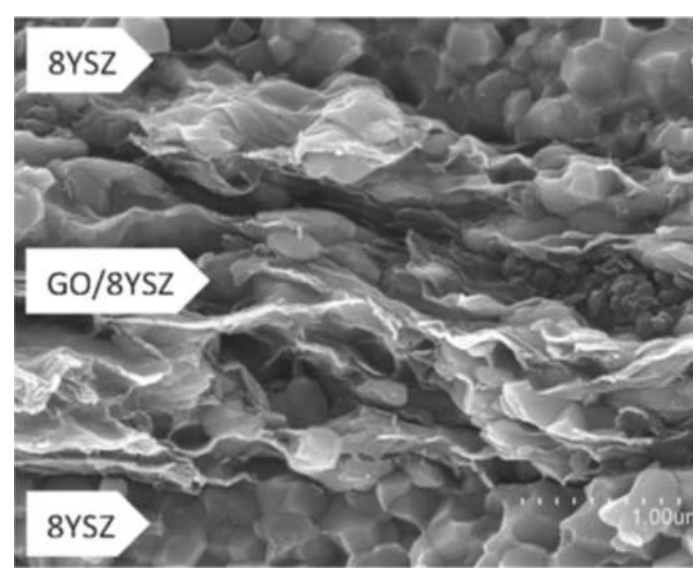

Figure 20. SEM micrograph of the fracture surface of a layered material based on uncoated (8YSZ) and coated (8YSZ/GO) layers [93].

An et al. [94] manufactured $\mathrm{ZrB}_{2} / \mathrm{GO}$ and $\mathrm{ZrB}_{2}-\mathrm{SiC} / \mathrm{GO}$ layered composites alternating ceramic layers with two different GO contents. The composite assembly process consisted of two consecutive steps. In the first one, the self-assembly of the GO5Z, GO30Z, GO5ZS and GO30ZS films, where 5 and 30 corresponded to the GO vol.\% content, and $\mathrm{Z}$ and $\mathrm{S}$ were $\mathrm{ZrB}_{2}$ and $\mathrm{SiC}$ ceramics, was carried out by vacuum-assisted filtration method of the 
corresponding ceramic/GO solutions. The addition of $\mathrm{SiC}$ particles (content not provided) led to more compacted films. In the second step, $\mathrm{ZrB}_{2} / \mathrm{GO}$ and $\mathrm{ZrB}_{2}-\mathrm{SiC} / \mathrm{GO}$ layered composites were produced alternatively stacking an undefined number of GO5Z-GO30Z films or GO5ZS-GO30ZS ones, respectively, and further SPS at $1950{ }^{\circ} \mathrm{C}$. GO were in situ thermally reduced to graphene during the SPS process. The flexural strength (measured by three points bending test) and the fracture toughness (determined by a single edge notched beam test) of sintered bars, cut with the testing surface parallel to the composite layers, increased in both layered composites as compared to bulk ceramics (Figure 21). In particular, increments of up to $28 \%$ and $223 \%$ for $\sigma_{\mathrm{f}}$ and $\mathrm{K}_{\mathrm{IC}}$, respectively, were attained for $\mathrm{ZrB}_{2} / \mathrm{GO}$ layered composites. The reason for the outstanding improvement in $\mathrm{K}_{\mathrm{IC}}$ was explained by the combination of various toughness mechanisms that occurred at different length scales, including the sliding of graphene nanosheets, graphene crack pulling out and bridging, crack branching, crack arrest and crack deflection.
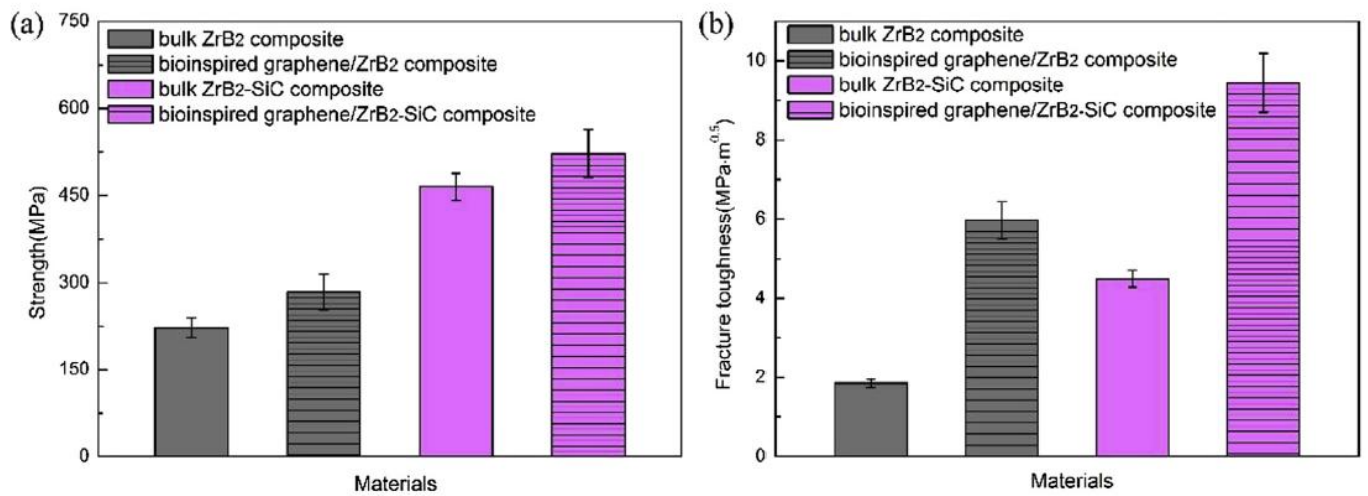

Figure 21. Flexural strength (a) and fracture toughness (b) of bulk $\mathrm{ZrB}_{2}$ and $\mathrm{ZrB}_{2}-\mathrm{SiC}$ composites and layered "bioinspired" graphene $/ \mathrm{ZrB}_{2}$ and graphene $/ \mathrm{ZrB}_{2}-\mathrm{SiC}$ composites [94]. 
At the present, only two works have been reported for the second processing approach, previously classified as "layered ceramic/graphene materials". Belmonte et al. [91] showed an innovative low cost and easily scalable method for fabricating multilayered graphene/ceramic structures, which consisted in stacking alternative layers of $\mathrm{Si}_{3} \mathrm{~N}_{4}$ powders and GO film, and further densification using the SPS technique at $1650{ }^{\circ} \mathrm{C}$. GO films were previously cut into disc shapes from A4 size GO film prepared from the chemically exfoliation and oxidation of graphite flakes. The whole fully densified structure was formed by $6 \mathrm{Si}_{3} \mathrm{~N}_{4}$ layers ( 4 inner ones of $400 \mu \mathrm{m}$ and 2 outer ones of $500 \mu \mathrm{m}$ ) and 5 GO films (200 nm each) that were in situ reduced to rGO during SPS (Figure 22). A continuous SiC interlayer of 300-350 nm of thickness with columnar grains oriented toward the interface was grown between $\mathrm{Si}_{3} \mathrm{~N}_{4}$ and rGO layers and promoted a good mechanical bonding between these layers. The authors analysed the electrical, thermal and mechanical properties of the layered material, which only contained a $0.03 \mathrm{vol} . \%$ of rGO in the whole structure. It showed strong directional electrical transport with an increased electrical conductivity of up to 16 orders of magnitude for the in-plane (parallel to the layers) direction as compared to bulk $\mathrm{Si}_{3} \mathrm{~N}_{4}$ ceramics; whereas was insulator in the throughthickness (perpendicular to the layers) direction. The heat flowed around 25\% faster in the in-plane direction, although lattice defects of rGO and thermal resistances at SiC-rGO interfaces acted as a thermal barrier decreasing the overall thermal conductivity of the structure. The increased electrical conductivity and reduced thermal conductivity is potentially useful for thermoelectric applications. $\mathrm{K}_{\mathrm{IC}}$ determined by surface crack in flexure method slightly increased (15\%) for the layered material compared with bulk $\mathrm{Si}_{3} \mathrm{~N}_{4}$ ceramics. Indentation tests performed in the ceramic layers showed a $42 \%$ improvement in 
$\mathrm{K}_{\mathrm{IC}}$ for cracks propagating perpendicular to the layers due to crack impingement and deflecting at the graphene layers.
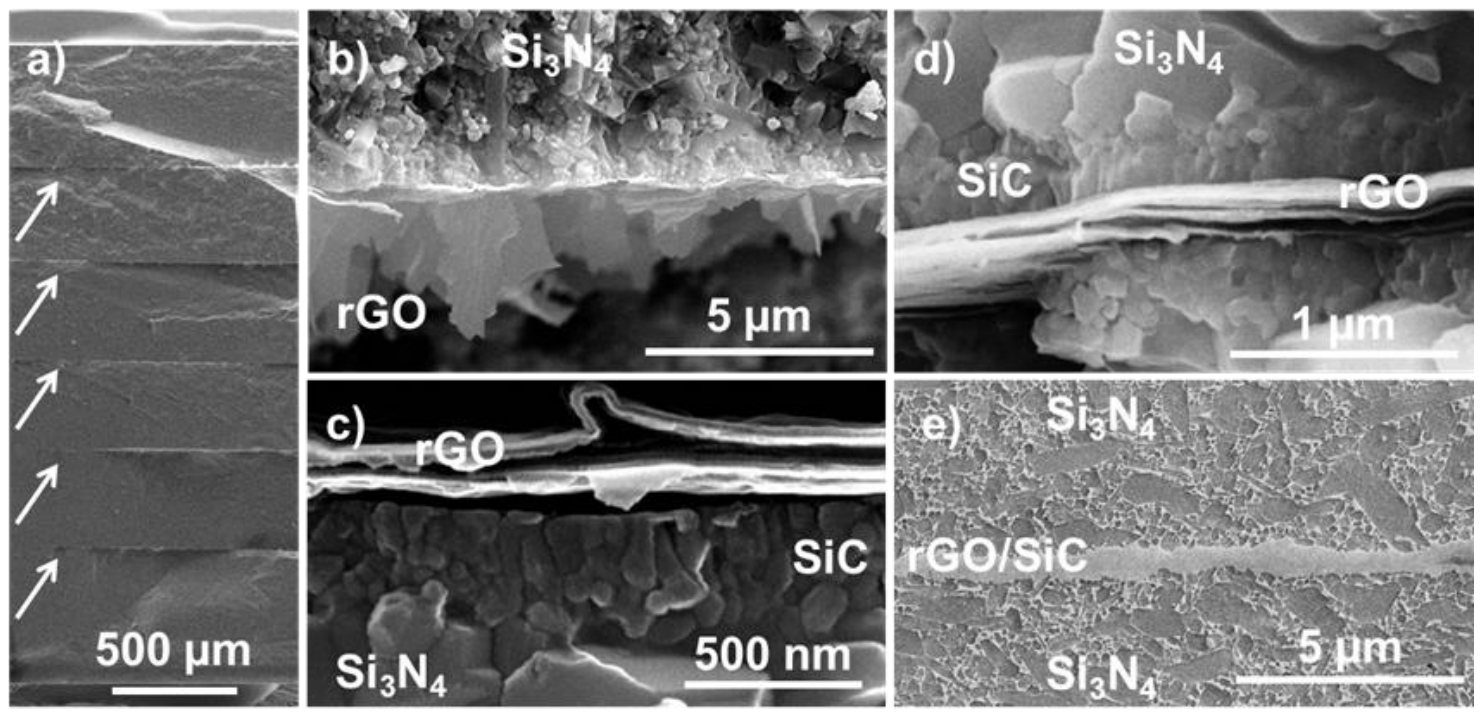

Figure 22. SEM micrographs at different magnifications of the fracture (a-d) and polished and plasma etched (e) surfaces corresponding to the cross-section of the multilayered $\mathrm{Si}_{3} \mathrm{~N}_{4} / \mathrm{rGO}$ material: a) whole system containing five rGO layers (pointed by arrows) and six $\mathrm{Si}_{3} \mathrm{~N}_{4}$ layers, b) graphene flakes protruding from the fracture surface after bending, c) and d) $\mathrm{SiC}$ layers formed by the reaction between the $\mathrm{Si}_{3} \mathrm{~N}_{4}$ matrix and the GO film, e) matrix grain distribution after the plasma etching process [91].

Finally, Zhuang et al. [92] reported a one-step method to create graphene/3C-SiC nanolayered structures using microwave plasma chemical vapour deposition (MWCVD) technique. In essence, 3C-SiC layers (4-10 nm thickness) and graphene sheets (2-5 nm thickness) were alternatively grown varying the reactive gas mixture containing $\mathrm{H}_{2}, \mathrm{CH}_{4}$ and tetramethylsilane. The electrical conductivity at room temperature of $4 \mu \mathrm{m}$ thickness nanolayered ceramic/graphene structure was $96.1 \mathrm{~S} \cdot \mathrm{cm}^{-1}$. 
Therefore, the above works have demonstrated the benefits of combining the layered concept and the use of graphene-based structures for achieving remarkable improvements in the materials functionality, although the research on this field is still in an embryo stage.

\subsection{Ceramic/graphene coatings}

Several methods have been used for deposition of ceramic/graphene composite coatings (Table 3), namely, electrochemical (ECD) and electrophoretic deposition (EPD) -the most widely applied - and vacuum plasma (VPS), atmospheric plasma (APS), flame (FS) and vacuum cold (VCS) spraying techniques.

In the colloidal processes (EPD and ECD), charged micro/nanoparticles in a suspension are deposited onto conductive substrates under an electrical field [95]. EPD is performed from low conductivity aqueous suspensions, whereas ECD is based on solution of salts (buffers), that is, from high conductivity suspensions; this induces high zeta potential $(\zeta)$ of particles in $\mathrm{EPD}$ as compared to $\mathrm{ECD}$ and, therefore, $\zeta$ plays a prominent role in EPD determining the stability of the suspension and the direction and migration velocity of the charged particles. Because low strength electric fields are utilized in ECD combined to the moderate $\zeta$ created by the high ionic strength buffer solutions, the migration of particles in ECD is generally insignificant and thin coatings are obtained because only particles present nearby vicinity of the electrode surface precipitate. The elevated $\zeta$ and high strength electric field yield in EPD produces significant migration of particles compared to ECD and, as a result, thicker coatings are obtained. On the other hand, thermal spraying techniques (APS, FS and VPS) are industrially implemented cost-effective methods based on heating and accelerating the source material towards the substrate [96]. The differences between these 
processes are the source of energy and the type of gun employed; plasma spraying developed the highest temperatures $(>10,000 \mathrm{~K})$ and then is the most effective for materials with high melting point; in oxygen-acetylene flame processes, particles attain lower temperatures (2500-4000 K) with particle velocities ranging from below 100 up to $2000 \mathrm{~m} \mathrm{~s}^{-1}$ for flame and high velocity oxyacetylene flame spraying systems, respectively. Despite the lower particle temperature and velocity achieved in the flame spraying process, it is a widely and commercially used method for low melting point materials.

As it can be seen in Table 3, almost all of the studied systems are bio-coatings over titanium or magnesium metallic substrates based on $\mathrm{HA}, \mathrm{CS}, \mathrm{ZrO}_{2}, \mathrm{SiO}_{2}$ and $\mathrm{TiO}_{2}$, containing either GO or GNP in amounts below 5 wt.\%. HA/graphene composite coatings have been by far the most studied systems up to know (Table 3). In spite of the low fracture toughness and wear resistance of HA and CS, their excellent bioactivity and biocompatibility make them good candidates for coating metallic biomedical implants in order to enhance its biocompatibility and accelerate early osseointegration. Composite coatings consisting on graphene nanoflakes dispersions within HA and CS matrices are then good solutions for enhancing the mechanical properties of the HA and CS coatings and, thus, the long-term performance of orthopedic-related implants in a biological environment. Particularly, GO emerged as an attractive precursor for HA-based composite coatings of implants as could promote the adhesion and proliferation of osteoblasts, and it exhibit potential antibacterial activity and induce apatite nucleation [97, 98].

Although main differences between the different methods should be related to the density and thickness of the coatings, these parameters are difficult to verify as they are not reported in the majority of documents. Analysed cross-sections of some of the coatings are 
presented in Figure 23, showing thickness in the $200 \mu \mathrm{m}$ range in the case of FS, $\sim 50 \mu \mathrm{m}$ for VCS and EPD and $\sim 10 \mu \mathrm{m}$ for ECD.

Table 3. Summary of the works reported on ceramic/graphene coatings (references are in parenthesis) indicating the processing method, studied system, approximate thickness when available and reported improved properties.

\begin{tabular}{|c|c|c|c|c|}
\hline Reference & Technique & Material & $\begin{array}{l}\text { Thickness } \\
\qquad(\mu \mathrm{m})\end{array}$ & Improved Properties \\
\hline Li et al. [99] & \multirow{4}{*}{ EPD } & $\begin{array}{c}\mathrm{HY} / \mathrm{HA} / \mathrm{GO} \\
(0.5,1,1.5 \text { wt. } \%) \\
\end{array}$ & ------ & corrosion \\
\hline Li et al [100] & & $\begin{array}{c}\text { HA/GO } \\
(2,5 \text { wt. } \%)\end{array}$ & $\sim 50 \mu \mathrm{m}$ & $\begin{array}{l}\text { corrosion, bonding strength and } \\
\text { biocompatibility }\end{array}$ \\
\hline Li et al [101] & & $\mathrm{SF} / \mathrm{HA} / \mathrm{GO}$ & ------ & $\begin{array}{l}\text { mechanical properties }(\mathrm{E} \text { and } \mathrm{H}) \text {, in } \\
\text { vitro hemo- and cito- compatibility }\end{array}$ \\
\hline Shi et al [102] & & $\begin{array}{l}\mathrm{CH} / \mathrm{HA} / \mathrm{GO} \\
(1,1.7 \text { wt. } \%)\end{array}$ & ------- & corrosion, biocompatibility \\
\hline $\begin{array}{l}\text { Zeng et al. } \\
\text { [103] }\end{array}$ & $\mathrm{ECD}$ & $\mathrm{HA} / \mathrm{GO}$ & $\sim 10 \mu \mathrm{m}$ & bonding and adhesion \\
\hline Liu et al. [104] & VCS & $\begin{array}{c}\text { HA/rGO } \\
(0.1,1 \text { wt. } \%)\end{array}$ & $\sim 50 \mu \mathrm{m}$ & $\begin{array}{l}\text { Toughness, adhesion, } \\
\text { biocompatibility }\end{array}$ \\
\hline $\begin{array}{c}\text { Jankovic et al. } \\
{[105]}\end{array}$ & \multirow{2}{*}{ EPD } & $\begin{array}{l}\text { HA/GNP } \\
(1 \mathrm{wt} . \%)\end{array}$ & ------- & $\begin{array}{l}\text { corrosion, mechanical properties (E } \\
\text { and } \mathrm{H} \text { ) }\end{array}$ \\
\hline $\begin{array}{c}\text { Jankovic et } \\
\text { al.[106] }\end{array}$ & & Silver/HA/GNP & ------- & corrosion, antibacterial, bioactivity \\
\hline $\begin{array}{c}\text { Gao et al. } \\
{[107]}\end{array}$ & laminate & $\mathrm{HA} / \mathrm{GO}$ & ------- & corrosion \\
\hline Xie et al. [62] & VPS & $\begin{array}{c}\text { CS/GNP } \\
(0.5,1.5,4 \text { wt. } \%)\end{array}$ & ------- & $\begin{array}{l}\text { wear, friction, } \\
\text { invitrocitocompatibility }\end{array}$ \\
\hline $\begin{array}{l}\text { Xie et al. } \\
\text { [108] }\end{array}$ & VPS & $\begin{array}{c}\text { CS/GNP } \\
(1.5 \text { wt. } \%)\end{array}$ & ------ & in vivo biocompatibility, Muy flojo \\
\hline Li et al. [60] & APS & $\begin{array}{l}\mathrm{ZrO} 2 / \mathrm{GNP} \\
(0.64 \text { wt. \%) }\end{array}$ & ------- & wear and friction \\
\hline $\begin{array}{l}\text { Kou et al. } \\
{[109]}\end{array}$ & $\begin{array}{l}\text { drop- } \\
\text { coating }\end{array}$ & $\mathrm{SiO} 2 / \mathrm{GO}$ & ------ & superhydrophilic \\
\hline $\begin{array}{c}\text { Garcia et al. } \\
{[110]}\end{array}$ & \multirow{3}{*}{ FS } & \multirow{3}{*}{$\begin{array}{c}\text { YAS/GNP } \\
(1.2,2.3 \mathrm{wt} \%)\end{array}$} & \multirow{3}{*}{$200 \mu \mathrm{m}$} & Electrical, thermal, mechanical \\
\hline $\begin{array}{c}\text { Garcia et al. } \\
{[111]}\end{array}$ & & & & Ablation resistance \\
\hline $\begin{array}{l}\text { Gomez- } \\
\text { Gomez et } \\
\text { al.[61] }\end{array}$ & & & & Wear and friction \\
\hline
\end{tabular}




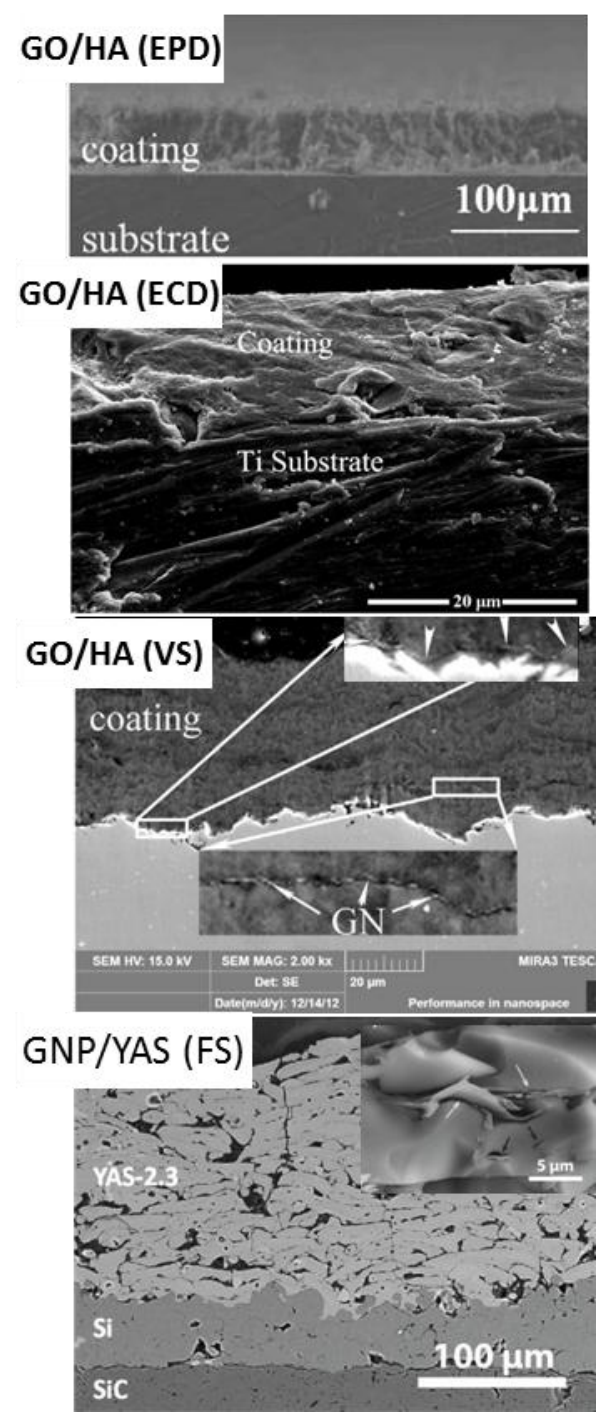

Figure 23. Top and cross section views on ceramic/graphene composites adapted from literature. HA and YAS correspond to hydroxyapatite and $\mathrm{Y}_{2} \mathrm{O}_{3}-\mathrm{Al}_{2} \mathrm{O}_{3}-\mathrm{SiO}_{2}$. The preparation method is included in brackets: electrophoretic deposition (EPD) [100], electrochemical deposition (ECD) [103], vacuum cold spray (VCS)[104] and flame spray (FS) $[110]$

Exceptions to the bio-coatings are: i) large-area superhydrophilic coatings fabricated by drop-casting using $\mathrm{SiO}_{2}$ nanoparticle-covered $\mathrm{GO}$ nanohybrids over inorganic (ceramic 
tiles), organic (polypropylene), and natural (lotus leaves) substrates, where $\mathrm{GO}_{-} \mathrm{SiO}_{2}$ was synthesized by the hydrolysis and condensation of tetraethylorthosilicate (TEOS) in the water-alcohol solution of GO under basic conditions at room temperature [109]; ii) glassceramic/graphene coatings for high temperature protection of aerospace components in thermal protection systems (TPS) $[61,110,111]$. Carbon fibre/carbon $\left(\mathrm{C}_{\mathrm{f}} / \mathrm{C}\right)$ and $\mathrm{C}_{\mathrm{f}} /$ silicon carbide $\left(\mathrm{C}_{\mathrm{f}} / \mathrm{SiC}\right)$ composites are foreseen as main components of the TPS, especially in zones that must bear temperatures above $1200{ }^{\circ} \mathrm{C}$ during the re-entry into the Earth atmosphere. However, $\mathrm{C}_{\mathrm{f}} / \mathrm{C}$ and $\mathrm{C}_{\mathrm{f}} / \mathrm{SiC}$ composites need to be protected against massive oxidation occurring above $500{ }^{\circ} \mathrm{C}$ in atmospheric conditions, and hybrid glass-ceramic (YAS)/graphene coatings are very promising materials for protecting them; they can be processed over $\mathrm{SiC}, \mathrm{C}_{\mathrm{f}} / \mathrm{SiC}$ and $\mathrm{C}_{\mathrm{f}} / \mathrm{C}$ substrates by thermal spraying [112] leading to anisotropic hybrid coatings with aligned GNP that exhibit enhanced damage tolerance, added electrical and thermal functionalities [110], better ablation [111], and wear resistances [61]. Besides, the self-healing capability of glass-ceramics at high temperature is an extra value.

In the case of thermal spraying methods, the amount of GNP added to the ceramic composition is reported to be reduced during high temperature deposition by 36 and $60 \%$ for APS of $\mathrm{ZrO}_{2} / \mathrm{GNP}$ powders of 20 - $50 \mu \mathrm{m}$ size [60] - from 1 to $0.64 \mathrm{wt} . \%$ - and FS of YAS/GNP spray dried granules of $30 \mu \mathrm{m}$ mean size - from 6.5 to $2.3 \mathrm{wt} . \%$ [110], respectively. In Figure 24, examples of feedstock used for thermal spraying are shown. 
The better GNP yield of APS can be explained because of the higher particle velocities and the involvement of inert gases as compared to flame spraying. These types of spraying processes induce a coating structure with a preferential surface parallel arrangement of the GNP which have been plenty demonstrated by micro-Raman studies on polished crosssection of flame sprayed YAS/GNP coatings [110]. As shown in Figure 25, the image constructed by filtering the intensity of the G-band of graphene shown flakes showing graphene Raman spectra located at the boundaries between splats (having aluminium 
silicate glass spectra). This peculiar GNP distribution imparts exceptional performance to the coatings, particularly, increased wear behaviour has been widely reported (Table 3) for YAS coating with 2.3 wt.\% (3.6 vol. \%) of GNP [61], APSed $\mathrm{ZrO}_{2} /$ GNs [60] and VPSed CS/GNP (1.5 wt.\%) coatings [62, 108], compared with the pure coatings (see Section 2). Besides, improved ablation resistance due to the presence of oriented GNP at the surface of the coating has also been proved [61].
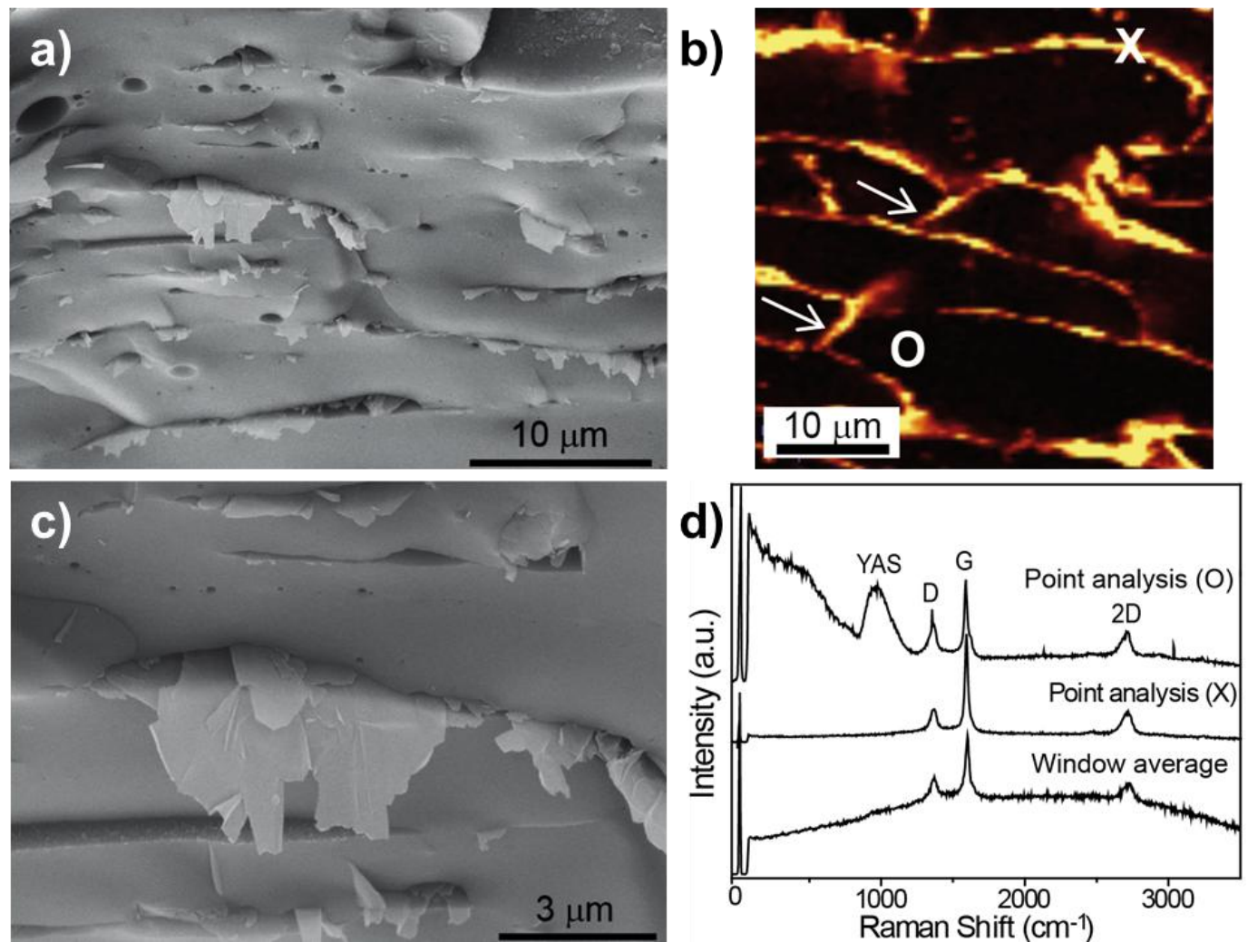

Figure 25. Fracture surface of a YAS/GNP coating showing flakes at the inter-splat boundaries (a,b), Raman map of the graphene G-band intensity done on the polished cross section of same coating (c), which clearly links the flakes with the graphene spectra (d).From reference [110]. 
Compared with pure HA coatings, HA/GO composite coatings $(\sim 50 \mu \mathrm{m}$ thick from Figure 24) with 0,2 and 5 wt.\% GO contents [100], obtained by EPD on Ti sheets and afterwards sintered/reduced at $600{ }^{\circ} \mathrm{C}$ for $1 \mathrm{~h}$, showed lower shrinkage during drying and sintering and reduced crack formation. For the highest GO content of $5 \mathrm{wt} . \%$ a relatively rough surface was observed that increased the natural bone in-growth. GO effectively increased by up to $113 \%$ the bonding strength of the coatings to the Ti substrate and also prevent peeling. Although no supporting data are included in the study, authors explained these results by a reduction in the thermal expansion coefficient mismatch between the coatings and $\mathrm{Ti}$ substrate by adding GO sheets into the HA layer, and an increased cohesive strength within the HA nanoparticles and GO nanofiller. Potentiodynamic polarization and electrochemical impedance spectroscopy studies indicated that the HA/GO composite coatings exhibited higher corrosion resistance in comparison with pure HA coatings in simulated body fluid (SBF). In addition, superior (around 95\% cell viability for 2 wt.\% GO/HA) in vitro biocompatibility were observed in comparison with HA coated and uncoated Ti substrate. The same reduced crack formation has been reported by JANKOVIC et al [105], who also obtained $\mathrm{Ca} / \mathrm{P}$ ratio closer to the stoichiometric value for GNP/HA (1wt.\%) coating and superior bioactivity as compared to the HA pure coating.

Cheng's group also developed by EPD ternary hybrid coatings of GO (up to 1.5 wt\%)/hyaluronic acid (HY)/HA [99], GO/silk fibroin(SF)/HA [101] and GO (up to 1.7 wt.\%)/chitosan(CHS)/HA [102] over Ti substrates. In these ternary systems, SF, HY and CHS act as charging additive and dispersion agent during EPD. Similar to HA/GO coatings, the addition of GO sheets -in these cases without any reducing treatmentincreased the deposition rate, inhibit cracks nucleation and propagation and provide 
improved protection of $\mathrm{Ti}$ substrate from corrosion as compared to the GO free coatings. In addition, good vitro biocompatibility to MG63 human osteosarcoma cells and decreased attachment of Staphylococcus aureus was reported in the case of GO-CHS-HA [102]. Silver/hydroxyapatite/graphene (Ag/HA/GNP) ternary composite coatings with similar improved properties were also produced by EPD; particularly, the composite coating showed bioactivity by a newly formed apatite layer in SBF with enhanced corrosion stability, as well as antibacterial activity and noncytotoxicity against healthy peripheral blood mononuclear cells [106].

Thinner HA/GO composite coatings of $\sim 10 \mu \mathrm{m}$ thickness have been fabricated by ECD on Ti substrate [103] (Figure 23) with similar results as EPD, that is, the addition of GO enhanced the crystallinity of deposited apatite particles and the bonding strength of the assynthesized composite coatings, and in vitro cell culture assessment showed better biocompatibility -improved MG63 cells adhesion, proliferation and differentiation - of composite coatings compared with the pure HA coating and pure Ti substrate. These authors provided evidence of $\mathrm{TiC}$ formation at the interface with the substrate that may play a potential role in the increased adhesion.

Finally, VCS allows developing HA/(up to $1 \mathrm{wt} . \%) \mathrm{rGO}$ composite coatings of $50 \mu \mathrm{m}$ thickness that retain intact the original nanostructure features and phases of both HA and rGO [104]. VCS is based on shock-loading solidification, which enables high deposition efficiency of nanosized powders (particle size $0.02-2 \mu \mathrm{m}$ ) at room temperature. The $\mathrm{HA} / \mathrm{rGO}$ composite coatings showed competitive adhesive strength and fracture toughness, and markedly enhanced attachment and proliferation of the osteoblast cells, which is most 
likely attributed to fast adsorption of key serum proteins like fibronectin with elongated stretching conformation on rGO.

\subsection{Cellular ceramic/graphene composites}

Although interest on three-dimensional (3D) porous graphene structures [113] started early because the many potential applications in many fields, and the same can be said for cellular polymer/graphene composites [114], the studies on cellular ceramic/graphene composites are just taking off. The main impulse is also provided by the multiple applications that cellular structures can provide; in concrete, we can enounce applications for thermal management, in catalysis, energy storage, sensors, bio-scaffolds, etc.

For 3D ceramic/graphene structures two types of methods materialize, those based in the use of templates and those corresponding to the additive manufacturing kind. In the first case, M. Zhou et al M. Zhou et al. [115] succeeded in growing graphene on $\mathrm{Al}_{2} \mathrm{O}_{3}$ foams using ambient pressure chemical vapour deposition (CVD) (Figure 26). The controlling of the carbothermic reduction occurring at the $\mathrm{Al}_{2} \mathrm{O}_{3}$ surface was essential during the initial stage of graphene nucleation to achieve a complete covering of $\mathrm{Al}_{2} \mathrm{O}_{3}$ particles and connection with neighbouring sheets They were also able to control the quality and layer number of graphene on $\mathrm{Al}_{2} \mathrm{O}_{3}$ as it can be finely tailored by changing the growth temperature and gas ratio. The potential applications of these hybrid structures in thermal transport and thermal energy storage devices was also put forward [116]. 


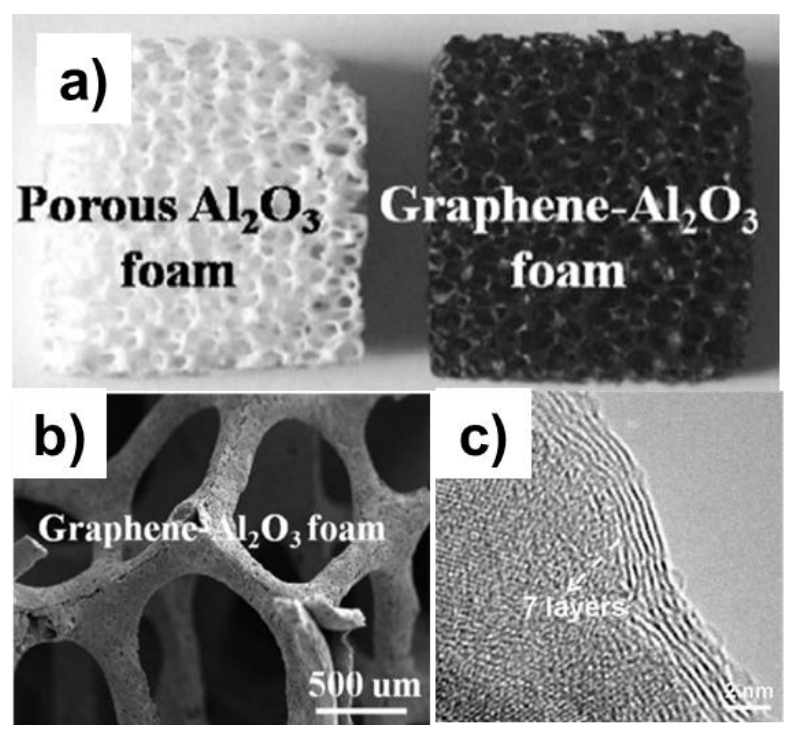

Figure 26. Images of (a) $\mathrm{Al}_{2} \mathrm{O}_{3}$ foam and the same type of structure but graphene-coated by CVD, (b) HRTEM image of the thin coating (7 graphene layers) on the $\mathrm{Al}_{2} \mathrm{O}_{3}$ template, c) SEM view of the graphene- $\mathrm{Al}_{2} \mathrm{O}_{3}$ foam. From reference [116].

Conversely, Mynbaeva et al. [117] employed porous SiC to form epitaxial graphene on the surface of $\mathrm{SiC}$. The porous $\mathrm{SiC}$ was created by anodizing $\mathrm{SiC}$ wafers in an aqueous solution of $\mathrm{HF}$, thus a layer of $\mathrm{s} \mathrm{SiC}$ with a micro-porous structure was formed in the bulk of the wafer. The samples were annealed at $\mathrm{T}=1500-1700^{\circ} \mathrm{C}$ in vacuum to favour thermal decomposition of the $\mathrm{SiC}$ on the surface.

Within the additive manufacturing methods, we can highlight the $3 \mathrm{D}$ printing by the socalled Robocasting method of SiC/GNP spanned nanostructures [118]. These scaffolds were assembled from pseudoplastic inks containing homogeneous mixtures of $\mathrm{SiC}$ ceramic powders and up to $20 \mathrm{vol} . \%$ of GNP, and densified by pressureless SPS at $1800^{\circ} \mathrm{C}$. They produced robust structures with compressive strengths in the range of $10-50 \mathrm{MPa}$ for corresponding densities of $0.8-1.6 \mathrm{~g} \cdot \mathrm{cm}^{-3}$ that showed directionality of the electrical 
conductivity with $\sigma_{x, y}$ values of up to $611 \mathrm{~S} \cdot \mathrm{m}^{-1}$ and $\sigma_{z}$ of up to $273 \mathrm{~S} \cdot \mathrm{m}^{-1}$ (axes defined by the extrusion and pilling up directions as shown in Figure 27). This anisotropy was determined by the design of the structure and also by the strong preferential orientation of the GNP within the rod during the printing process with their c-axis perpendicular to the extruding direction and showing a shell where GNP are parallel aligned with the rod wall.

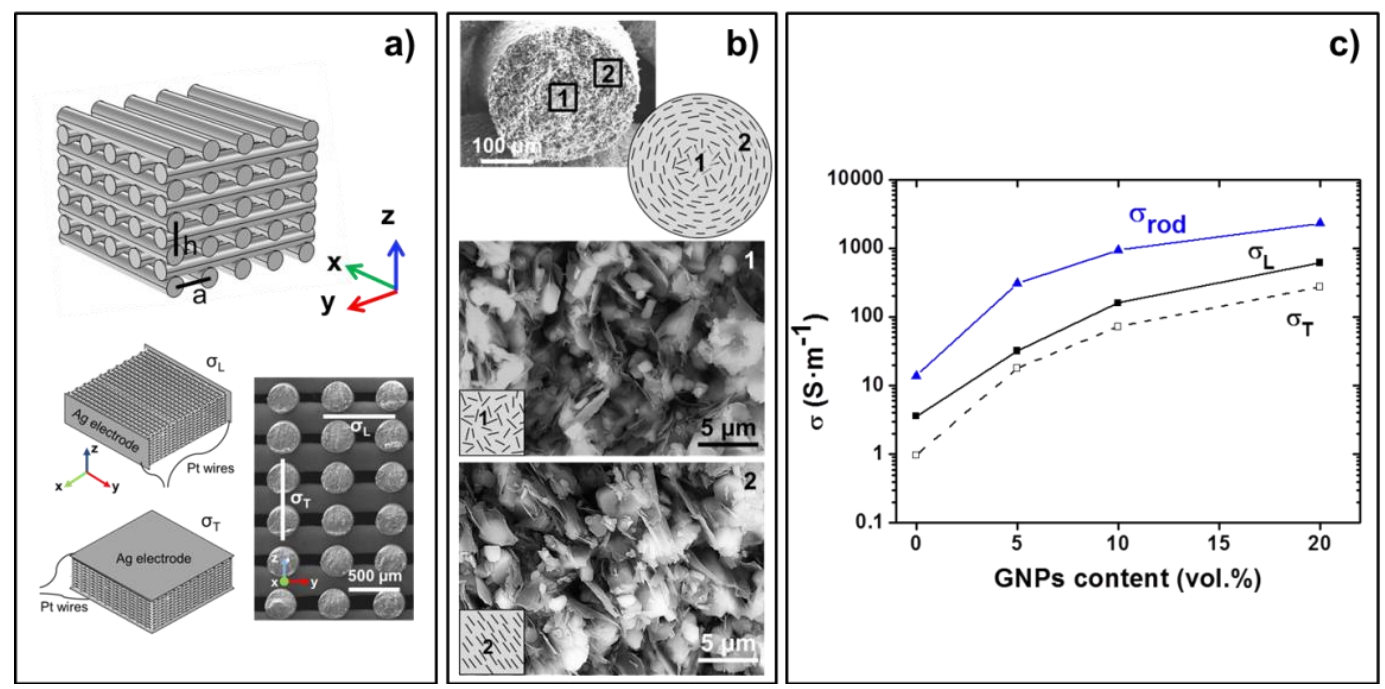

Figure 27. Schematic of scaffold for robocasting with indication of the axis, structures and orientation for the electrical conductivity are depicted and corresponding SEM image of the printed structures with the measured directions (a). SEM image of a single filament in the scaffold and higher magnifications views of the distinct zones in the filament (shown in the drawings) (b). Electrical conductivity data for the two orientations indicated in (a) plotted with results for a single rod. From reference [118].

Pierin et al. [119] used an alternative approach by direct printing inks of a pre-ceramic silicone polymer containing a very small amount of GO, although the addition of crosslinked silicone resin particles was necessary to achieve pintable inks. Pyrolysis was carried 
out by heating at $1000{ }^{\circ} \mathrm{C}$, since obtaining a SiOC amorphous matrix. Authors observed that with the addition of small amounts of GO flakes, the printed scaffolds show a better retention of the structure upon heating and reduced shrinkage and cracks formation with respect to the GO-free scaffolds (Figure 29).

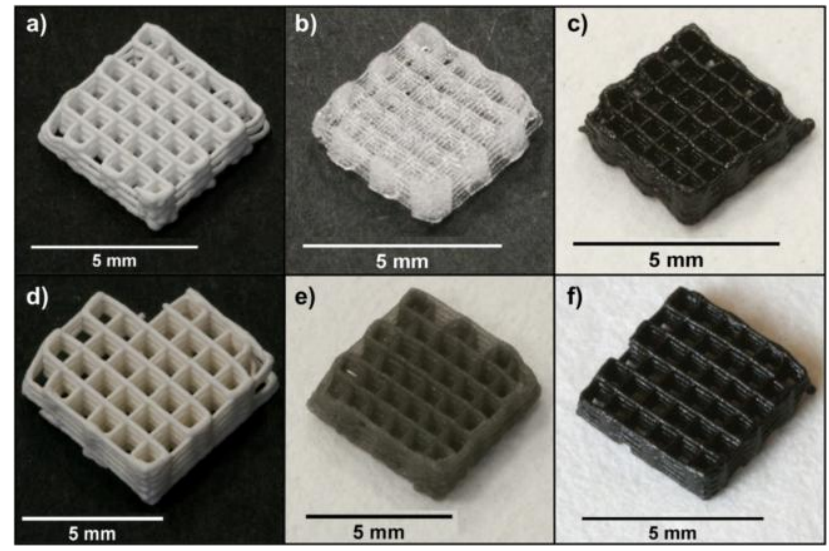

Figure 29. Optical images of the scaffolds printed using a silicone resin pre-ceramic polymer at different processing steps: (a) as printed (no GO added); (b) after cross-linking (no GO added); (c) after pyrolysis (no GO added); (d) as printed (0.1 wt\% GO); (e) after cross-linking (0.1 wt\% GO); (f) after pyrolysis (0.1 wt\% GO). From reference [119].

Azhari and EToyserkani [120] reported porous graphene-HA structures by powder-bed additive manufacturing. The structures were built by spreading a layer of the powdered mixture of HA and GO (0.4 to 04 wt.\%) and an aqueous binder in a layer by layer manner. The addition of GO increased the load bearing capacity of these structures.

Finally, we can mention a different route to the above described that consisted in the fabrication silicon oxycarbide cellular materials by stereolithography of light curable polymers Eckel et al. [121]. They used a novel self-propagating photopolymer waveguide 
technology, which seems to reduce the need for additives that control scatter and UV absorption. The pyrolized structures (treated at $1000{ }^{\circ} \mathrm{C}$ in argon) showed mass loss of $42 \%$ and bout $30 \%$ of linear shrinkage, being fully dense with no porosity or surface cracks. Compressive strength of $45 \mathrm{MPa}$ was measured on a honeycomb structure with a density of $0.4 \mathrm{~g} \cdot \mathrm{cm}^{-3}$. This structures may be considered as graphene containing ceramic assemblies as it show amorphous regions with $\beta-\mathrm{SiC}$ crystallites and graphitic nanodomains.

\section{Concluding remarks}

A substantial number of publications presently exist on ceramic/graphene composites even though this is a relatively new field. The focus of attention for researchers has been on the toughness enhancement, which is a common battlefield for ceramics, where these new fillers have mostly succeeded in probing their unquestionable reinforcing effect. It is plainly demonstrated as well the electrical functionality induced in these composites, which results in a promising effect of ultimately structural ceramics. Also quite remarkable is the better performance of these composites under friction and even more noteworthy in wear conditions, which are particularly interesting considering that this is a prime field of application for ceramics. In the case of thermal transport, the augment of the thermal conductivity is not a general rule for these composites but the high directionality brought by these graphene fillers has generally been proved, that might be quite advantageous in some applications like for thermal management and thermal protection. Finally, the adaptably of graphene nanostructures to many ceramic processing methods has been shown, making real new developments, as for example layered composites, coatings or 3D assemblies. Although a lot remains to be learnt in matters like specific reinforcement models, stability 
with temperature, directionality in the composites properties or proper control of the nanostructures dispersibility, the results already achieved are encouraging and consequently the prospective for these new materials is favourable.

\section{Acknowledgments}

This work was supported by JECS Trust and the Spanish Government (projects MAT201232944 and MAT2015-67437-R).

\section{References}

[1] Zhu Y, Murali S, Cai W, Li X, Suk JW, Potts JR, et al. Graphene and Graphene Oxide:

Synthesis, Properties, and Applications. Advanced Materials. 2010;22(35):3906-24.

[2] Soldano C, Mahmood A, Dujardin E. Production, properties and potential of graphene. Carbon. 2010;48(8):2127-50.

[3] Lotya M, Hernandez Y, King PJ, Smith RJ, Nicolosi V, Karlsson LS, et al. Liquid Phase Production of Graphene by Exfoliation of Graphite in Surfactant/Water Solutions. Journal of the American Chemical Society. 2009;131(10):3611-20.

[4] Ciesielski A, Samori P. Graphene via sonication assisted liquid-phase exfoliation. Chemical Society Reviews. 2014;43(1):381-98.

[5] Porwal H, Grasso S, Reece MJ. Review of graphene-ceramic matrix composites. Advances in Applied Ceramics. 2013;112(8):443-54. 
[6] Markandan, K., Chin, J. K., \& Tan, M. T. Recent progress in graphene based ceramic composites: a review. Journal of Materials Research. 2016;1-23.

https://doi.org/10.1557/jmr.2016.390

[7] Nieto, A., Bisht, A., Lahiri, D., Zhang, C., \& Agarwal, A. (2016). Graphene reinforced metal and ceramic matrix composites: a review. International Materials Reviews, 1-62. http://dx.doi.org/10.1080/09506608.2016.1219481

[8] Wang K, Wang YF, Fan ZJ, Yan J, Wei T. Preparation of graphene nanosheet/alumina composites by spark plasma sintering. Materials Research Bulletin. 2011;46(2):315-8.

[9] Fan Y. Preparation and electrical properties of graphene nanosheet/ $\mathrm{Al}_{2} \mathrm{O}_{3}$ composites. Carbon. 2010;48(6):1743.

[10] Walker L, Marotto V, Rafiee M, Koratkar N, Corral E. Toughening in graphene ceramic composites. ACS nano. 2011;5(4):3182-90.

[11] Kun P. Determination of structural and mechanical properties of multilayer graphene added silicon nitride-based composites. Ceramics international. 2011.

[12] Ramirez C, Miranzo P, Belmonte M, Isabel Osendi M, Poza P, Vega-Diaz SM, et al. Extraordinary toughening enhancement and flexural strength in $\mathrm{Si}_{3} \mathrm{~N}_{4}$ composites using graphene sheets. Journal of the European Ceramic Society. 2014;34(2):161-9.

[13] Tapaszto O, Tapaszto L, Lemmel H, Puchy V, Dusza J, Balazsi C, et al. High orientation degree of graphene nanoplatelets in silicon nitride composites prepared by spark plasma sintering. Ceramics International. 2016;42(1):1002-6.

[14] Dusza J, Morgiel J, Duszova A, Kvetkova L, Nosko M, Kun P, et al. Microstructure and fracture toughness of $\mathrm{Si}_{3} \mathrm{~N}_{4}+$ graphene platelet composites. Journal of the European Ceramic Society. 2012;32(12):3389-97. 
[15] Centeno A, Rocha VG, Alonso B, Fernandez A, Gutierrez-Gonzalez CF, Torrecillas R, et al. Graphene for tough and electroconductive alumina ceramics. Journal of the European Ceramic Society. 2013;33(15-16):3201-10.

[16] Porwal H, Tatarko P, Grasso S, Khaliq J, Dlouhy I, Reece MJ. Graphene reinforced alumina nano-composites. Carbon. 2013;64:359-69.

[17] Lee B, Koo MY, Jin SH, Kim KT, Hong SH. Simultaneous strengthening and toughening of reduced graphene oxide/alumina composites fabricated by molecular-level mixing process. Carbon. 2014;78:212-9.

[18] Kvetková L. Fracture toughness and toughening mechanisms in graphene platelet reinforced $\mathrm{Si}_{3} \mathrm{~N}_{4}$ composites. Scripta materialia. 2012;66(10):793-6.

[19] Belmonte M, Nistal A, Boutbien P, Roman-Manso B, Osendi MI, Miranzo P. Toughened and strengthened silicon carbide ceramics by adding graphene-based fillers. Scripta Materialia. 2016;113:127-30.

[20] Chen F, Jin D, Tyeb K, Wang B, Han Y-H, Kim S, et al. Field assisted sintering of graphene reinforced zirconia ceramics. Ceramics International. 2015;41(4):6113-6.

[21] Shin J-H, Hong S-H. Fabrication and properties of reduced graphene oxide reinforced yttria-stabilized zirconia composite ceramics. Journal of the European Ceramic Society. 2014;34(5):1297-302.

[22] Tonello KPdS, Padovano E, Badini C, Biamino S, Pavese M, Fino P. Fabrication and characterization of laminated $\mathrm{SiC}$ composites reinforced with graphene nanoplatelets. Materials Science and Engineering a-Structural Materials Properties Microstructure and Processing. 2016;659:158-64. 
[23] Yadhukulakrishnan GB, Karumuri S, Rahman A, Singh RP, Kalkan AK, Harimkar SP. Spark plasma sintering of graphene reinforced zirconium diboride ultra-high temperature ceramic composites. Ceramics International. 2013;39(6):6637-46.

[24] Nieto A, Lahiri D, Agarwal A. Graphene NanoPlatelets reinforced tantalum carbide consolidated by spark plasma sintering. Materials Science and Engineering a-Structural Materials Properties Microstructure and Processing. 2013;582:338-46.

[25] Tan Y, Zhang H, Peng S. Electrically conductive graphene nanoplatelet/boron carbide composites with high hardness and toughness. Scripta Materialia. 2016;114:98-102.

[26] Liu L, Wang Y, Li X, Xu L, Cao X, Wang Y, et al. Enhancing Toughness in Boron Carbide with Reduced Graphene Oxide. Journal of the American Ceramic Society. 2016;99(1):257-64.

[27] Zhang X, An Y, Han J, Han W, Zhao G, Jin X. Graphene nanosheet reinforced ZrB $2_{2^{-}}$ $\mathrm{SiC}$ ceramic composite by thermal reduction of graphene oxide. Rsc Advances. 2015;5(58):47060-5.

[28] Chen B, Liu X, Zhao X, Wang Z, Wang L, Jiang W, et al. Preparation and properties of reduced graphene oxide/fused silica composites. Carbon. 2014;77:66-75.

[29] Liu X, Li J, Yu X, Fan H, Wang Q, Yan S, et al. Graphene nanosheet/titanium carbide composites of a fine-grained structure and improved mechanical properties. Ceramics International. 2016;42(1):165-72.

[30] Cheng X, He R, Qu Z, Chen M. Characterisation of graphene nanoplatelets reinforced hot pressed Ti3SiC2 ceramic. Advances in Applied Ceramics. 2016;115(1):43-8.

[31] Tan YQ, Luo H, Zhang HB, Peng SM. Graphene nanoplatelet reinforced boron carbide composites with high electrical and thermal conductivity. Journal of the European Ceramic Society. 2016;36(11):2679-87. 
[32] Zhang L, Liu W, Yue C, Zhang T, Li P, Xing Z, et al. A tough graphene nanosheet/hydroxyapatite composite with improved in vitro biocompatibility. Carbon. $2013 ; 61: 105-15$.

[33] Liu Y, Huang J, Li H. Synthesis of hydroxyapatite-reduced graphite oxide nanocomposites for biomedical applications: oriented nucleation and epitaxial growth of hydroxyapatite. Journal of Materials Chemistry B. 2013;1(13):1826-34.

[34] Zhu JT, Wong HM, Yeung KWK, Tjong SC. Spark Plasma Sintered Hydroxyapatite/Graphite Nanosheet and Hydroxyapatite/Multiwalled Carbon Nanotube Composites: Mechanical and in Vitro Cellular Properties. Advanced Engineering Materials. $2011 ; 13(4): 336-41$.

[35] Wang XT, Padture NP, Tanaka H. Contact-damage-resistant ceramic/single-wall carbon nanotubes and ceramic/graphite composites. Nature Materials. 2004;3(8):539-44.

[36] Seiner H, Ramirez C, Koller M, Sedlak P, Landa M, Miranzo P, et al. Elastic properties of silicon nitride ceramics reinforced with graphene nanofillers. Materials \& Design. 2015;87:675-80.

[37] Mai YW, Lawn BR. Crack-Interface Grain Bridging as a Fracture Resistance Mechanism in Ceramics: II, Theoretical Fracture Mechanics Model. Journal of the American Ceramic Society. 1987;70(4):289-94.

[38] Evans AG. Perspective on the development of high-toughness ceramics. Journal of the American Ceramic Society. 1990;73(2):187-206.

[39] Ahmad I, Islam M, Abdo HS, Subhani T, Khalil KA, Almajid AA, et al. Toughening mechanisms and mechanical properties of graphene nanosheet-reinforced alumina.

Materials \& Design. 2015;88:1234-43. 
[40] Ramirez C, Osendi MI. Toughening in ceramics containing graphene fillers. Ceramics International. 2014;40(7):11187-92.

[41] Campbell GH, Ruhle M, Dalgleish BJ, Evans AG. Whisker toughening: a comparison between aluminum oxide and silicon nitride toughened with silicon carbide. Journal of the American Ceramic Society. 1990;73(3):521-30.

[42] Ovid'ko IA, Sheinerman AG. Toughening due to crack deflection in ceramic- and metal-graphene nanocomposites. Reviews on Advanced Materials Science. 2015;43(12):52-60.

[43] Seiner H, Sedlak P, Koller M, Landa M, Ramirez C, Isabel Osendi M, et al. Anisotropic elastic moduli and internal friction of graphene nanoplatelets/silicon nitride composites. Composites Science and Technology. 2013;75:93-7.

[44] Tan Y, Luo H, Zhang H, Peng S. Graphene nanoplatelet reinforced boron carbide composites with high electrical and thermal conductivity. Journal of the European Ceramic Society. 2016;36(11):2679-87.

[45] Lee C, Wei X, Kysar JW, Hone J. Measurement of the elastic properties and intrinsic strength of monolayer graphene. Science. 2008;321(5887):385-8.

[46] Gomez-Navarro C, Burghard M, Kern K. Elastic properties of chemically derived single graphene sheets. Nano Letters. 2008;8(7):2045-9.

[47] Michel KH, Verberck B. Theory of the elastic constants of graphite and graphene. physica status solidi (b). 2008;245.

[48] Hvizdos P, Dusza J, Balazsi C. Tribological properties of $\mathrm{Si}_{3} \mathrm{~N}_{4}$-graphene nanocomposites. Journal of the European Ceramic Society. 2013;33(12):2359-64. 
[49] Belmonte M, Ramirez C, Gonzalez-Julian J, Schneider J, Miranzo P, Isabel Osendi M. The beneficial effect of graphene nanofillers on the tribological performance of ceramics. Carbon. 2013;61:431-5.

[50] Balko J, Hvizdos P, Dusza J, Balazsi C, Gamcova J. Wear damage of $\mathrm{Si}_{3} \mathrm{~N}_{4}$-graphene nanocomposites at room and elevated temperatures. Journal of the European Ceramic Society. 2014;34(14):3309-17.

[51] Rutkowski P, Stobierski L, Zientara D, Jaworska L, Klimczyk P, Urbanik M. The influence of the graphene additive on mechanical properties and wear of hot-pressed $\mathrm{Si}_{3} \mathrm{~N}_{4}$ matrix composites. Journal of the European Ceramic Society. 2015;35(1):87-94.

[52] Maros BM, Nemeth AK, Karoly Z, Bodis E, Maros Z, Tapaszto O, et al. Tribological characterisation of silicon nitride/multilayer graphene nanocomposites produced by HIP and SPS technology. Tribology International. 2016;93:269-81.

[53] Kim HJ, Lee SM, Oh YS, Yang YH, Lim YS, Yoon DH, et al. Unoxidized Graphene/Alumina Nanocomposite: Fracture- and Wear-Resistance Effects of Graphene on Alumina Matrix. Scientific Reports. 2014;4.

[54] Gutierrez-Gonzalez CF, Smirnov A, Centeno A, Fernandez A, Alonso B, Rocha VG, et al. Wear behavior of graphene/alumina composite. Ceramics International. 2015;41(6):7434-8.

[55] Yazdani B, Xu F, Ahmad I, Hou XH, Xia YD, Zhu YQ. Tribological performance of Graphene/Carbon nanotube hybrid reinforced $\mathrm{Al}_{2} \mathrm{O}_{3}$ composites. Scientific Reports. 2015;5. [56] Zhang, C., Nieto, A., \& Agarwal, A. Ultrathin graphene tribofilm formation during wear of $\mathrm{Al}_{2} \mathrm{O}_{3}$-graphene composites. Nanomaterials and Energy. 2016;5:1-9. 
[57] Llorente J, Roman-Manso B, Miranzo P, Belmonte M. Tribological performance under dry sliding conditions of graphene/silicon carbide composites. Journal of the European Ceramic Society. 2016;36(3):429-35.

[58] Porwal H, Tatarko P, Saggar R, Grasso S, Mani MK, Dlouhy I, et al. Tribological properties of silica-graphene nano-platelet composites. Ceramics International. 2014;40(8):12067-74.

[59] Li Z., Khun N.W., Tang X.-Z., Liu E., Khor K.A. Mechanical, tribological and biological properties of novel 45S5 Bioglasss ${ }^{\circledR}$ composites reinforced with in situ reduced graphene oxide, J. Mech. Behav. Biomed. Mater. 2017;65:77-89..

[60] Li HQ, Xie YT, Li K, Huang LP, Huang SS, Zhao BZ, et al. Microstructure and wear behavior of graphene nanosheets-reinforced zirconia coating. Ceramics International. 2014;40(8):12821-9.

[61] Gómez-Gómez A., Nistal A., García E., Osendi M. I., Belmonte M., Miranzo P., The decisive role played by graphene nanoplatelets on improving the tribological performance of $\mathrm{Y}_{2} \mathrm{O}_{3}-\mathrm{Al}_{2} \mathrm{O}_{3}-\mathrm{SiO}_{2}$ glass coatings, Mater. Design. 2016;112:449-455.

[62] Xie YT, Li HQ, Zhang C, Gu X, Zheng XB, Huang LP. Graphene-reinforced calcium silicate coatings for load-bearing implants. Biomedical Materials. 2014;9(2).

[63] Celik Y, Celik A, Flahaut E, Suvaci E. Anisotropic mechanical and functional properties of graphene-based alumina matrix nanocomposites. Journal of the European Ceramic Society. 2016;36(8):2075-86.

[64] Ramirez C, Figueiredo FM, Miranzo P, Poza P, Osendi MI. Graphene nanoplatelet/silicon nitride composites with high electrical conductivity. Carbon. 2012;50(10):3607-15. 
[65] Roman-Manso B, Domingues E, Figueiredo FM, Belmonte M, Miranzo P. Enhanced electrical conductivity of silicon carbide ceramics by addition of graphene nanoplatelets. Journal of the European Ceramic Society. 2015;35(10):2723-31.

[66] Fan YC, Jiang W, Kawasaki A. Highly Conductive Few-Layer Graphene/ $\mathrm{Al}_{2} \mathrm{O}_{3}$ Nanocomposites with Tunable Charge Carrier Type. Advanced Functional Materials. 2012;22(18):3882-9.

[67] Ramirez C. Electrical conductivity maps in graphene nanoplatelet/silicon nitride composites using conducting scanning force microscopy. Carbon. 2011;49(12):3873. [68] Yun C, Feng YB, Qiu T, Yang J, Li XY, Yu L. Mechanical, electrical, and thermal properties of graphene nanosheet/aluminum nitride composites. Ceramics International. 2015;41(7):8643-9.

[69] Ramirez C, Vega-Diaz SM, Morelos-Gomez A, Figueiredo FM, Terrones M, Osendi MI, et al. Synthesis of conducting graphene/ $\mathrm{Si}_{3} \mathrm{~N}_{4}$ composites by spark plasma sintering. Carbon. 2013;57:425-32.

[70] Simsek I. N. G., Nistal A., Garcia E., Pérez-Coll D., Miranzo P., Osendi M.I. The effect of graphene nanoplatelets on the thermal and electrical properties of aluminum nitride ceramics. Journal European Ceramic Society. 2016, sent for publication.

[71] Estili M, Wu W-W, Khazaei M, Sakka Y. Mechanically reliable thermoelectric (TE) nanocomposites by dispersing and embedding TE-nanostructures inside a tetragonal $\mathrm{ZrO} 2$ matrix: the concept and experimental demonstration in graphene oxide-3YSZ system. Science and Technology of Advanced Materials. 2014;15(1).

[72] Ramirez C, Leboran V, Rivadulla F, Miranzo P, Osendi MI. Thermopower and hall effect in silicon nitride composites containing thermally reduced graphene and pure graphene nanosheets. Ceramics International. 2016;42(9):11341-7. 
[73] Balandin AA. Thermal properties of graphene and nanostructured carbon materials. Nature Materials. 2011;10(8):569-81.

[74] Pop E, Varshney V, Roy AK. Thermal properties of graphene: Fundamentals and applications. Mrs Bulletin. 2012;37(12):1273-81.

[75] Rutkowski P, Klimczyk P, Jaworska L, Stobierski L, Dubiel A. Thermal properties of pressure sintered alumina-graphene composites. Journal of Thermal Analysis and Calorimetry. 2015;122(1):105-14.

[76] Jankovsky O, Simek P, Sedmidubsky D, Huber S, Pumera M, Sofer Z. Towards highly electrically conductive and thermally insulating graphene nanocomposites: $\mathrm{Al}_{2} \mathrm{O}_{3}$-graphene. Rsc Advances. 2014;4(15):7418-24.

[77] Miranzo P, Garcia E, Ramirez C, Gonzalez-Julian J, Belmonte M, Isabel Osendi M. Anisotropic thermal conductivity of silicon nitride ceramics containing carbon nanostructures. Journal of the European Ceramic Society. 2012;32(8):1847-54. [78] Xia HY, Zhang X, Shi ZQ, Zhao CJ, Li YF, Wang JP, et al. Mechanical and thermal properties of reduced graphene oxide reinforced aluminum nitride ceramic composites. Materials Science and Engineering a-Structural Materials Properties Microstructure and Processing. 2015;639:29-36.

[79] Kovalcikova A, Sedlak R, Rutkowski P, Dusza J. Mechanical properties of boron carbide plus graphene platelet composites. Ceramics International. 2016;42(1):2094-8. [80] Li QS, Zhang YJ, Gong HY, Sun HB, Li T, Guo X, et al. Effects of graphene on the thermal conductivity of pressureless-sintered SiC ceramics. Ceramics International. 2015;41(10):13547-52. 
[81] Roman-Manso B, Chevillotte Y, Osendi MI, Belmonte M, Miranzo P. Thermal conductivity of silicon carbide composites with highly oriented graphene nanoplatelets. Journal of the European Ceramic Society. 2016;36(16):3987-93.

[82] Rutkowski P, Dubiel A, Piekarczyk W, Ziabka M, Dusza J. Anisotropy in thermal properties of boron carbide-graphene platelet composites. Journal of the European Ceramic Society. 2016;36(12):3051-7.

[83] Rutkowski P, Kata D, Jankowski K, Piekarczyk W. Thermal properties of hot-pressed aluminum nitride-graphene composites. Journal of Thermal Analysis and Calorimetry. 2016;124(1):93-100.

[84] Rutkowski P, Stobierski L, Gorny G. Thermal stability and conductivity of hot-pressed $\mathrm{Si}_{3} \mathrm{~N}_{4}$-graphene composites. Journal of Thermal Analysis and Calorimetry. 2014;116(1):321-8.

[85] De Pablos A, Osendi M, Miranzo P. Effect of microstructure on the thermal conductivity of hot-pressed silicon nitride materials. Journal of the American Ceramic Society. 2002;85(1):200-6.

[86] Ramírez Maglione M.C., PhD Thesis: Materiales multifuncionales de nitruro de silicio con nanoestructuras reforzanters basadas en grafeno, 2014, http://hdl.handle.net/10486/662461.

[87] Clegg WJ, Kendall K, Alford NM, Button TW, Birchall JD. A simple way to make tough ceramics. Nature. 1990;347(6292):455-7.

[88] Wegst UGK, Bai H, Saiz E, Tomsia AP, Ritchie RO. Bioinspired structural materials. Nature Materials. 2015;14(1):23-36.

[89] Luo H, Xiao P, Huang L, Hong W. Dielectric properties of C-f- $\mathrm{Si}_{3} \mathrm{~N}_{4}$ sandwich composites prepared by gelcasting. Ceramics International. 2014;40(6):8253-9. 
[90] Rincon A, Chinelatto ASA, Moreno R. Tape casting of alumina/zirconia suspensions containing graphene oxide. Journal of the European Ceramic Society. 2014;34(7):1819-27.

[91] Belmonte M, Nistal A, Cruz-Silva R, Morelos-Gomez A, Terrones M, Miranzo P, et al. Directional Electrical Transport in Tough Multifunctional Layered Ceramic/Graphene Composites. Advanced Electronic Materials. 2015;1(9).

[92] Zhuang H, Yang B, Heuser S, Huang N, Fu HY, Jiang X. Graphene/3C-SiC Hybrid Nanolaminate. Acs Applied Materials \& Interfaces. 2015;7(51):28508-17.

[93] Rincon A, Moreno R, Gutierrez-Gonzalez CF, Sainz R, Salvador MD, Borrell A. Colloidal processing of fully stabilized zirconia laminates comprising graphene oxideenriched layers. Journal of the European Ceramic Society. 2016;36(7):1797-804.

[94] An Y, Han J, Zhang X, Han W, Cheng Y, Hu P, et al. Bioinspired high toughness graphene/ZrB ${ }_{2}$ hybrid composites with hierarchical architectures spanning several length scales. Carbon. 2016;107:209-16.

[95] Besra L, Liu M. A review on fundamentals and applications of electrophoretic deposition (EPD). Progress in Materials Science. 2007;52(1):1-61.

[96] Pawlowski, L. The Science and Engineering of Thermal Spray Coatings. Second ed., John Wiley \& Sons, New York, 2008.

[97] Chung C, Kim YK, Shin D, Ryoo SR, Hong BH, Min DH. Biomedical Applications of Graphene and Graphene Oxide. Accounts of Chemical Research. 2013;46(10):2211-24.

[98] Liu HY, Xi PX, Xie GQ, Shi YJ, Hou FP, Huang L, et al. Simultaneous Reduction and Surface Functionalization of Graphene Oxide for Hydroxyapatite Mineralization. Journal of Physical Chemistry C. 2012;116(5):3334-41. 
[99] Li M, Liu Q, Jia ZJ, Xu XC, Shi YY, Cheng Y, et al. Electrophoretic deposition and electrochemical behavior of novel graphene oxide-hyaluronic acid-hydroxyapatite nanocomposite coatings. Applied Surface Science. 2013;284:804-10.

[100] Li M, Liu Q, Jia ZJ, Xu XC, Cheng Y, Zheng YF, et al. Graphene oxide/hydroxyapatite composite coatings fabricated by electrophoretic nanotechnology for biological applications. Carbon. 2014;67:185-97.

[101] Li M, Xiong P, Mo MS, Cheng Y, Zheng YF. Electrophoretic-deposited novel ternary silk fibroin/graphene oxide/hydroxyapatite nanocomposite coatings on titanium substrate for orthopedic applications. Frontiers of Materials Science. 2016;10(3):270-80. [102] Shi YY, Li M, Liu Q, Jia ZJ, Xu XC, Cheng Y, et al. Electrophoretic deposition of graphene oxide reinforced chitosan-hydroxyapatite nanocomposite coatings on Ti substrate. Journal of Materials Science-Materials in Medicine. 2016;27(3).

[103] Zeng YX, Pei XB, Yang SY, Qin H, Cai H, Hu SS, et al. Graphene oxide/hydroxyapatite composite coatings fabricated by electrochemical deposition. Surface \& Coatings Technology. 2016;286:72-9.

[104] Liu Y, Dang Z, Wang Y, Huang J, Li H. Hydroxyapatite/graphene-nanosheet composite coatings deposited by vacuum cold spraying for biomedical applications: Inherited nanostructures and enhanced properties. Carbon. 2014;67:250-9. [105] Jankovic A, Erakovic S, Mitric M, Matic IZ, Juranic ZD, Tsui GCP, et al. Bioactive hydroxyapatite/graphene composite coating and its corrosion stability in simulated body fluid. Journal of Alloys and Compounds. 2015;624:148-57.

[106] Jankovic A, Erakovic S, Vukasinovic-Sekulic M, Miskovic-Stankovic V, Park SJ, Rhee KY. Graphene-based antibacterial composite coatings electrodeposited on titanium for biomedical applications. Progress in Organic Coatings. 2015;83:1-10. 
[107] Gao F, Xu CY, Hu HT, Wang Q, Gao YY, Chen H, et al. Biomimetic synthesis and characterization of hydroxyapatite/graphene oxide hybrid coating on $\mathrm{Mg}$ alloy with enhanced corrosion resistance. Materials Letters. 2015;138:25-8.

[108] Xie YT, Li HQ, Ding CX, Zheng XB, Li K. Effects of graphene plates' adoption on the microstructure, mechanical properties, and in vivo biocompatibility of calcium silicate coating. International Journal of Nanomedicine. 2015;10:3855-63.

[109] Kou LA, Gao C. Making silica nanoparticle-covered graphene oxide nanohybrids as general building blocks for large-area superhydrophilic coatings. Nanoscale.

2011;3(2):519-28.

[110] Garcia E, Nistal A, Khalifa A, Essa Y, de la Escalera FM, Osendi MI, et al. Highly Electrically Conducting Glass-Graphene Nanoplatelets Hybrid Coatings. Acs Applied Materials \& Interfaces. 2015;7(32):17656-62.

[111] Garcia E, Nistal A, Osendi MI, Miranzo P. Superior performance of ablative glass coatings containing graphene nanosheets, J. Am. Ceram. Soc. 2016, in press, DOI:

$10.1111 /$ jace. 14447 .

[112] Marraco-Borderas C., Nistal A., García E., Sainz M.A., Martín de la Escalera F., Essa Y., Miranzo P., Adhesion of $\mathrm{Y}_{2} \mathrm{O}_{3}-\mathrm{Al}_{2} \mathrm{O}_{3}-\mathrm{SiO}_{2}$ coatings to typical aerospace substrates, Bol. Soc. Esp. Ceram. Vidrio. 2016;55, 127-135.

[113] Huang XD, Qian K, Yang J, Zhang J, Li L, Yu CZ, et al. Functional Nanoporous Graphene Foams with Controlled Pore Sizes. Advanced Materials. 2012;24(32):4419-23. [114] Wang M, Duan XD, Xu YX, Duan XF. Functional Three-Dimensional Graphene/Polymer Composites. Acs Nano. 2016;10(8):7231-47. 
[115] Zhou M, Lin TQ, Huang FQ, Zhong YJ, Wang Z, Tang YF, et al. Highly Conductive Porous Graphene/Ceramic Composites for Heat Transfer and Thermal Energy Storage. Advanced Functional Materials. 2013;23(18):2263-9.

[116] Zhou M, Bi H, Lin TQ, Lu XJ, Wan DY, Huang FQ, et al. Heat transport enhancement of thermal energy storage material using graphene/ceramic composites. Carbon. 2014;75:314-21.

[117] Mynbaeva MG, Sitnikova AA, Kirilenko DA, Kotousova IS. Graphene/silicon carbide-based scaffolds. Journal of Physics D-Applied Physics. 2012;45(33).

[118] Roman-Manso B, Figueiredo FM, Achiaga B, Barea R, Perez-Coll D, MorelosGomez A, et al. Electrically functional 3D-architectured graphene/SiC composites. Carbon. 2016;100:318-28.

[119] Pierin G, Grotta C, Colombo P, Mattevi C. Direct Ink Writing of micrometric SiOC ceramic structures using a preceramic polymer. Journal of the European Ceramic Society. 2016;36(7):1589-94.

[120] Azhari A, Toyserkani E, Villain C. Additive Manufacturing of GrapheneHydroxyapatite Nanocomposite Structures. Int J Appl Ceram Technol. 2015;12(1):8-17. [121] Eckel ZC, Zhou CY, Martin JH, Jacobsen AJ, Carter WB, Schaedler TA. 3D printting additive manufacturing of polymer-derived ceramics. Science. 2016;351(6268):58-62. 